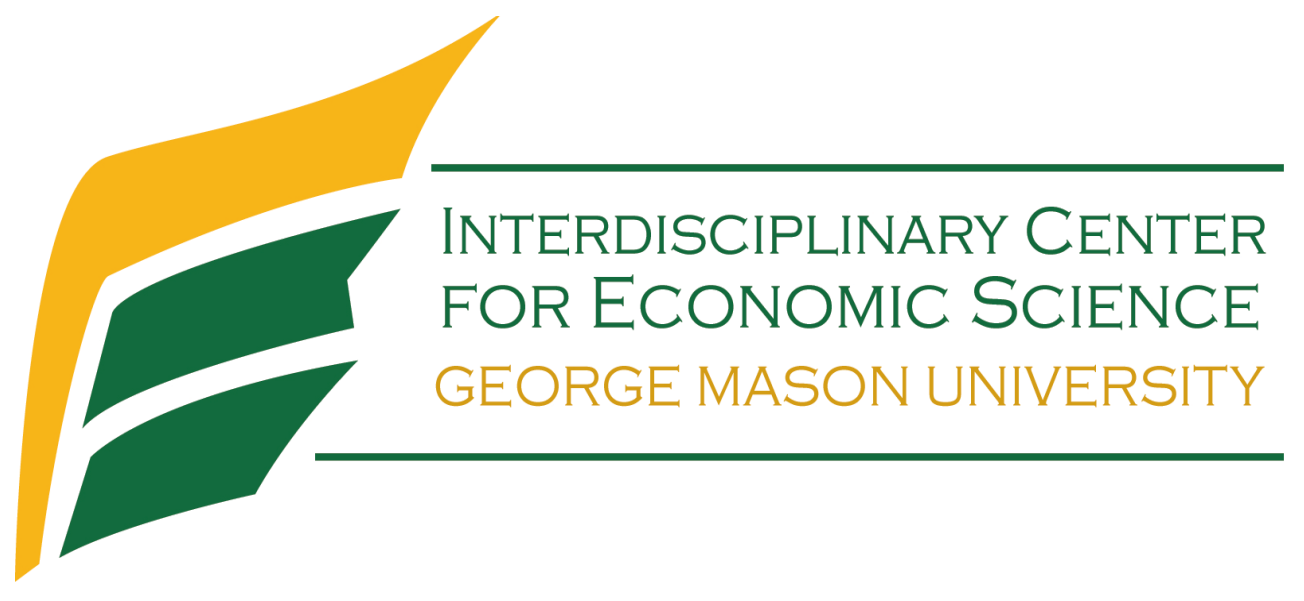

\title{
Competition with Indivisibilities and Few Traders
}

Cesar Martinelli, Jianxin Wang, and Weiwei Zheng

July 2019

Discussion Paper

Interdisciplinary Center for Economic Science

4400 University Drive, MSN 1B2, Fairfax, VA 22030

Tel: +1-703-993-4850 Fax: +1-703-993-4851

ICES Website: http://ices.gmu.edu

ICES RePEc Archive Online at: http://edirc.repec.org/data/icgmuus.html 


\title{
Competition with Indivisibilities and Few Traders*
}

\author{
César Martinelli Jianxin Wang Weiwei Zheng \\ George Mason University
}

July 25, 2019

\begin{abstract}
We study minimal conditions for competitive behavior with few agents. We adapt the strategic market game of Dubey (1982), Simon (1984) and Benassy (1986) to an indivisible good environment. We show that all Nash equilibrium outcomes with active trading are competitive if and only if there are at least two intramarginal traders in each side of the market. Unlike previous formulations, this condition can be verified directly by checking the set of competitive equilibria. In laboratory experiments, the condition we provide turns out to be enough to induce competitive results. Moreover, the performance of a sealed-bid auction following the rules of the strategic market game approaches that of its dynamic counterpart, the double auction, over time.
\end{abstract}

\section{Introduction}

Ever since the classic contributions of Cournot (1838) and Bertrand (1883), the question of whether a market with a small number of traders can achieve competitive outcomes has been a matter of debate. In the model proposed by Cournot, the market price is a function of aggregate quantity, and sellers decide how much to supply to the market. As a consequence, a large number of sellers in the market are required to approximate competitive behavior. Bertrand proposed an alternative model in which sellers choose prices, and the quantity a seller sells depends on the demand at the price chosen by the seller. By competing on prices, having two sellers in the market is enough to bring the price down to a competitive level.

The modern literature on strategic market games, pioneered by Dubey and Shubik (1980), Dubey (1982), Simon (1984) and Benassy (1986), revisits the topic of competition with few traders, paying attention to trading rules. Instead of sellers having only price or quantity in the strategy space, these authors consider an environment in

*Martinelli: cmarti33egmu.edu. Wang: jwang38@gmu.edu. Zheng: wzheng5egmu.edu. We thank Dan Houser, Kevin McCabe, Thomas Stratmann, Maurice Kugler, and participants at the 30th Stony Brook International Conference on Game Theory for helpful comments. 
which buyers and sellers submit price-quantity pairs to a clearing house, which acts as a profit-maximizing middleman, and allocates trades accordingly. In line with Bertrand's model, having a large number of traders is not indispensable for the competitiveness of Nash equilibrium outcomes in strategic market games. Dubey (1982), Simon (1984) and Benassy (1986) prove that, under certain trading rules, having two active sellers and two active buyers in a Nash equilibrium is sufficient to make the outcome competitive.

In this study, we propose a strategic market game applicable to markets with indivisible commodities. The sufficient condition for the equivalence of Nash equilibrium and competitive equilibrium outcomes obtained by previous literature in a divisible commodity setting still holds in our indivisible commodity setting. We provide a necessary and sufficient condition for equivalence: as long as there are at least two intramarginal traders on one side of the market, and two weakly intramarginal traders on the other side, the outcomes of any Nash equilibrium with trade will be competitive. Unlike previous work, our condition relies on the characteristics of the set of competitive equilibria, and place no requirement on Nash equilibria other than the occurrence of trade. In particular, our theorem includes contestable markets, in which a single active seller sells in the market at the competitive price, into the set of economies covered by the equivalence result.

A well-known mechanism for convergence to competitive outcomes in laboratory experiments is the (continuous) double auction, which is widely applied to markets with indivisible goods. The double auction mechanism is known to have robust convergence to competitive equilibrium in markets with as few as eight traders (Smith, 1982; Smith et al., 1982), without revelation of other traders' reservation values. A double auction market comprised of two buyers and three sellers, which involved the smallest number of traders in existing studies, showed a strong tendency toward competitive price despite an unexpected institutional change and few traders (Smith, 1980). The sealed-bid auction we propose here is a static version of the double auction. In a double auction mechanism, bids and asks are ranked in descending and ascending orders respectively. A transaction can happen at any time of the trading period when a valid bid is no lower than a valid ask, and higher ranked offers have the priority to trade. Our sealed-bid auction follows the rules of the strategic market game: as in a call market, bids/asks are collected once per trading period, and traders do not observe others' offers.

A reason for studying the performance of static institutions is that, despite the possible achievement of high efficiency, implementing and maintaining a dynamic institution in real life can be resource demanding. Efforts made to avoid information delay in stock markets is one of the examples (Laughlin et al., 2014). Taking into account the cost of organizing the market, a static institution could be preferable if it works as well as a dynamic one, or if the difference in performance can be compensated by the implementation cost. Among existing laboratory studies comparing the dynamic and static institutions, both Smith et al. (1982) and Friedman and Ostroy (1995) include a comparison of the double auction mechanism with a sealed double auction. Regardless of the possible non-competitive outcome in Nash equilibrium (Dubey and Shubik, 1980), in both studies, the call market mechanism approaches the efficiency of the double auction mechanism over time in experimental markets with eight or more 
traders.

In our laboratory experiment, we compare the performance of our strategic market institution with the performance of the double auction institution in two market environments: one in which all Nash equilibrium outcomes are competitive, and one in which only one of the sellers is intramarginal (i.e. a monopoly) so that some Nash equilibrium outcomes are non-competitive. Markets in our laboratory experiment have two buyers and two sellers - the minimal size allowing for the equivalence of Nash equilibrium and competitive equilibrium outcomes. Besides being useful for comparisons with our static institution, the small market size in our double auction experiments serves a boundary test for the double auction mechanism's convergence to competitive outcomes.

In the absence of monopoly power, the results from our experiment confirm the double auction institution's robust convergence to competitive outcomes even when there are very few traders. When monopoly power exists, higher trading price and lower trading volume (and thus, an efficiency loss) can be observed under the double auction compared to the environment without monopoly. Under our static institution, prices and trading volume converge to competitive levels over time both with and without monopoly power. Efficiency under the static institution remains below efficiency under the double auction, but seemingly converges over time. Estimated price asymptotes suggest that in the long run, the double auction may perform worse in terms of efficiency in monopoly environments than the static institution as the monopolist is better able to learn to exploit market power, though this does not happen in the horizon of our experiment. It is an interesting and open question whether the convergence to competitive outcomes for the static institution even in the presence of monopoly power is robust to learning in the long run and to variations in the parameters describing the economy.

In our laboratory experiment, as in other market experiments, traders are informed about their own valuations but not about the valuations of other traders. Thus, in using a strategic market game to explain behavior in the lab, we are following what Friedman and Ostroy (1995) call the "as-if Nash equilibrium complete information approach," the underlying idea of which is that "although traders' information in the experiments is far from complete, it is possible for them to learn to use the relevant 'complete information' strategies" (p. 23). Judging by a conventional indicator, Selten's (1991) predictive success index, our results suggest that such learning is more successful in competitive than in monopolistic markets.

The rest of the paper is organized as follows. Section 2 gives a formal description of the economy. Section 3 gives a detailed explanation of the strategic market mechanism. Section 4 contains the theorems of coincidence of Nash equilibrium and competitive equilibrium. Section 5 and section 6 describe the experimental design and results respectively. Section 7 concludes. Proofs for the propositions and theorems, and instructions and quizzes for the experiment are collected in the appendix. 


\section{The economy}

We describe a general equilibrium model related to laboratory experiments. Our notation follows Friedman and Ostroy (1995). There are two goods, a divisible 'money' and a traded good that can only be traded in indivisible units. Let $I=B \cup S$ be the set of individuals, classified as either buyers $(B)$ or sellers $(S)$. Each $i \in I$ is defined by a vector $\left(r_{i 1}, \ldots, r_{i k}\right)$, where $r_{i j}$ indicates the reservation value for the $j^{\text {th }}$ unit of the traded good. The parameter $k \geq 1$ indicates the maximum number of units of the traded good that an individual can buy or sell. For each $i \in B$, reservation values decrease with the quantity demanded: $r_{i 1} \geq \cdots \geq r_{i k} \geq 0$. For each $i \in S$, reservation values increase with the quantity supplied $0 \leq r_{i 1} \leq \cdots \leq r_{i k}$.

Each trader's utility is given by

$$
u_{i}\left(q_{i}, m_{i}\right)=\left\{\begin{array}{ll}
\delta_{i} \sum_{j=1}^{\left|q_{i}\right|} r_{i j}+m_{i} & \text { if } q_{i} \neq 0 \\
m_{i} & \text { if } q_{i}=0
\end{array},\right.
$$

where

$$
\delta_{i}=\left\{\begin{array}{ll}
1 & \text { if } i \in B \\
-1 & \text { if } i \in S
\end{array},\right.
$$

and $q_{i} \in Q_{i}$ is the quantity of the good traded by $i$ and $m_{i} \in \mathfrak{R}$ are the money holdings of $i$. We let $Q_{i}=\{0,1, \ldots, k\}$ if $i \in B$ and $Q_{i}=\{0,-1, \ldots,-k\}$ if $i \in S$, so that supply is described as negative demand. We assume that initial endowment of money of each individual is equal to 0 ; note that individuals are allowed negative money holdings.

Keeping fixed the sets of buyers and sellers and $k$, an economy $r \in \mathfrak{R}_{+}^{k|I|}$ is described by a set of vector of reservation values that are weakly decreasing for each buyer and weakly increasing for each seller, as described above. Given an economy $r$, an allocation (of the indivisible good) is a vector $q=\left(q_{i}\right) \in \times_{i \in I} Q_{i}$ and an outcome is a vector $(q, m)$ where $q$ is an allocation and $m \in \mathfrak{R}^{|I|}$.

Denote by $\xi(r)$ the set of competitive equilibria for an economy $r$. A competitive equilibrium $(p, q) \in \xi(r)$ is a price $p \in \mathfrak{N}_{+}$and an allocation $q$ such that

1. (utility maximization) for each $i, u_{i}\left(q_{i},-p q_{i}\right) \geq u_{i}\left(q_{i}^{\prime},-p q_{i}^{\prime}\right)$ for all $q_{i}^{\prime} \in Q_{i}$.

2. (market clearance) $\sum_{i \in I} q_{i}=0$.

By utility maximization, if $(p, q)$ is a competitive equilibrium for economy $r$, then

- for every $i \in B$, either $q_{i}=0$ and $r_{i 1} \leq p$, or $0<q_{i}<k$ and $r_{i q_{i}} \geq p \geq r_{i, q_{i}+1}$, or $q_{i}=k$ and $r_{i k} \geq p$.

- for every $i \in S$, either $q_{i}=0$ and $r_{i 1} \geq p$, or $-k<q_{i}<0$ and $r_{i\left|q_{i}\right|} \leq p \leq r_{i,\left|q_{i}\right|+1}$, or $q_{i}=-k$ and $r_{i k} \leq p$.

Note that a competitive equilibrium $(p, q)$ induces the outcome $(q, m)=\left(q,\left(-p q_{i}\right)\right)$. 
It is easy to prove that for any economy $r$, there is a competitive equilibrium. We can order the units that sellers can supply in ascending order according to their reservation values, and the units that buyers can demand in descending order according to their reservation values, to obtain the familiar supply and demand curves. Equilibrium prices and allocations can be obtained by the crossing of the supply and demand curves. As it is well-known for economies with quasi-linear preferences, the set of competitive allocations is the set of solutions to the problem of maximizing social surplus, that is

$$
\max _{q \in Q} \sum_{i \in I} \sum_{0 \leq j \leq\left|q_{i}\right|} \delta_{i} r_{i j}
$$

where $Q=\left\{q: q_{i} \in Q_{i}, \sum_{i} q_{i}=0\right\}$ is the set of feasible allocations.

Trade is positive in every competitive equilibrium if and only if

$$
\min _{i \in S} r_{i 1}<\max _{i \in B} r_{i 1}
$$

As we will see, an important condition for the equivalence between competitive equilibrium outcomes and the outcomes of a strategic game is that there are at least two trading individuals in each side of the market.

The related work of Dubey (1982), Simon (1984) and Benassy (1986) feature divisible commodities under the usual assumptions of continuous, increasing marginal costs for each seller, and positive, continuous, decreasing marginal utility of consumption for each buyer. Note that in economies with divisible units active traders compete "at the margin," in the sense that in a competitive equilibrium the marginal utility of consumption and the marginal cost of production for the last unit are equated to the price for all active traders. Our main result illustrates that competition at the margin is unnecessary for the equivalence between competitive and strategic outcomes.

\section{The strategic market game}

The strategic market mechanism we use is adapted from Simon (1984). Each individual submits a price-quantity offer $\left(\widetilde{p}_{i}, \widetilde{q}_{i}\right)$ to the clearing house, where $\widetilde{p}_{i} \geq 0$ and $\widetilde{q}_{i} \in Q_{i}$. Intuitively, each individual offers to trade up to $\left|\widetilde{q}_{i}\right|$ units of the traded good at the price $\widetilde{p}_{i}$. Denote the set of feasible offers for individual $i$ by

$$
W_{i}=\left\{\left(\widetilde{p}_{i}, \widetilde{q}_{i}\right): \widetilde{p}_{i} \geq 0 ; \widetilde{q}_{i} \in Q_{i}\right\}
$$

Given an offer profile $w \in W=\times_{i \in I} W_{i}$, the set of feasible allocation vectors for the clearing house is

$$
\begin{aligned}
Y(w)=\left\{\left(y_{1}, \ldots y_{n}\right):\right. & 0 \leq y_{i} \leq \widetilde{q}_{i}, \text { if } i \in B ; \\
& 0 \geq y_{i} \geq \widetilde{q}_{i}, \text { if } i \in S ; \\
& \sum_{i} y_{i}=0 ; \\
& \left.y_{i} \in \mathbb{Z}\right\} .
\end{aligned}
$$


Note that $Y(w)$ is a finite set. Conditions (1) and (2) guarantee that trade is voluntary, i.e. individuals do not end up trading more than what they offered. Condition (3) ensures that the market clears and the clearing house keeps no inventory. Condition (4) conveys the assumption that the good is indivisible.

After the clearing house chooses an allocation $y=\left(y_{1}, \ldots, y_{n}\right) \in Y(w)$, individual $i$ receives $y_{i}$ units of the traded good and earns an amount of money equal to $-\widetilde{p}_{i} y_{i}$. We assume that the clearing house allocates trade to maximize the arbitrage profit, $\sum_{i \in I} y_{i} \widetilde{p}_{i}$, as if the clearing house buys units from the sellers and sells them to buyers at the agents' proposed prices. Thus, given an offer profile $w$, the resulting allocation $y$ must satisfy

$$
y \in \Pi(w)=\left\{y \in Y(w): \sum_{i \in I} y_{i} \widetilde{p}_{i} \geq \sum_{i \in I} y_{i}^{\prime} \widetilde{p}_{i} \text { for all } y^{\prime} \in Y(w)\right\} .
$$

Intuitively, as in Dubey (1982), buying offers are ranked in a descending order by price while the quantities offered are accumulated to form the demand curve, and selling offers are ranked in an ascending order by price while the quantities offered are accumulated to form the supply curve. The clearing house extracts the surplus between the supply and demand, as Figure 1 illustrates. That is, the clearing house chooses a competitive equilibrium allocation for a fictitious economy $\tilde{r}$ given by

$$
\widetilde{r}_{i j}=\left\{\begin{array}{ll}
\widetilde{p}_{i} & \text { if } 1 \leq j \leq\left|\widetilde{q}_{i}\right| \\
0 & \text { if }\left|\widetilde{q}_{i}\right|<j \leq k \text { and } i \in B \\
+\infty & \text { if }\left|\widetilde{q}_{i}\right|<j \leq k \text { and } i \in S
\end{array},\right.
$$

and appropriates the social surplus.

In scenario (a) of Figure $1, \Pi(w)$ is a singleton set. To maximize the arbitrage profit, the clearing house would fulfill all demand and supply to the left of the dashed line. The dotted area is the profit for the clearing house, and the profit is positive in this case. In scenario (b), $\Pi(w)$ contains two allocations if units A and B are offered by different sellers, depending on which of the two sellers is allowed to sell the last unit. In scenario (c), the clearing house gets the same profit allocating $q_{1}$ or $q_{2}>q_{1}$ units. Similarly, in scenario (d), buying and selling $q$ units gives the same profit for the clearing house as making no trade.

To make trade happen whenever possible, following Simon (1984), we assume that the clearing house chooses an allocation from the set

$$
\begin{array}{r}
F(w)=\{y \in \Pi(w): \text { there is no } \phi \in \Pi(w) \\
\text { such that } \left.\phi \neq y \text { and }\left|\phi_{i}\right| \geq\left|y_{i}\right| \text { for all } i \in I\right\} .
\end{array}
$$

That is, the clearing house does not choose allocations that are ray-dominated. Then in scenario (c), $q_{2}$ units will be bought and sold, and in scenario (d), $q$ units will be traded. We still have two allocations in $F(w)$ in scenario (b) if units A and B are offered by different sellers. We assume that the clearing house chooses randomly according to the distribution $\mu_{w}$ that gives probability $\mu_{w}(y)>0$ to each allocation $y \in F(w)$ and probability $\mu_{w}(y)=0$ to every other allocation in $Y(w)$ such that $\sum_{y \in F(w)} \mu_{w}(y)=1$.

Given this market mechanism, define an active trader given offer profile $w$ as a trader that has positive probability to trade. In other words, agent $i$ is an active trader 


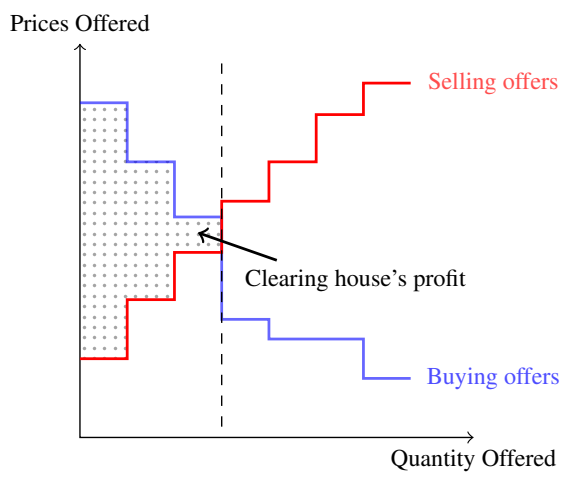

(a)

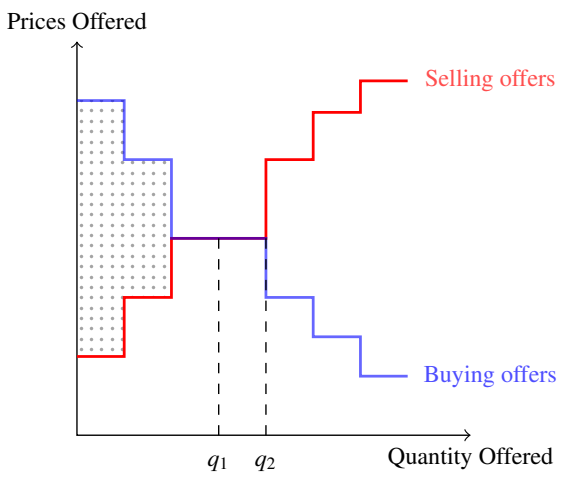

(c)

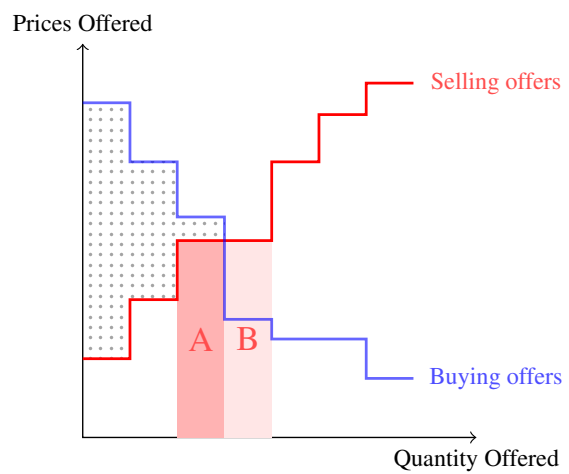

(b)

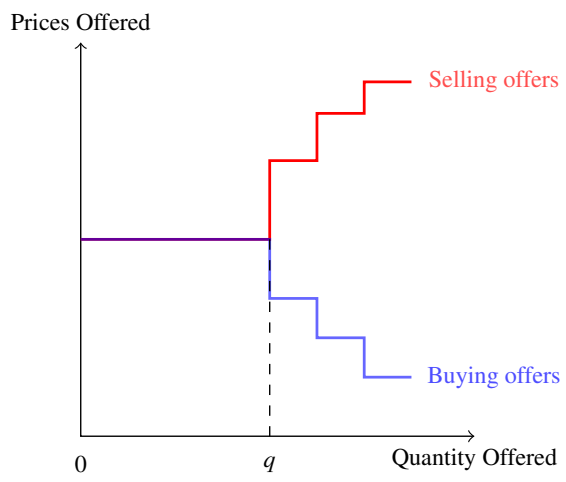

(d)

Figure 1: Arbitrage profit for the clearing house

given offer profile $w$ if there exists $y \in F(w)$ such that $y_{i} \neq 0$. Furthermore, denote by $A S(w)$ the set of active sellers, and $A B(w)$ the set of active buyers given offer profile $w$.

Propositions 1-6 in the Appendix provide a characterization on $F(w)$ that is used in later proofs.

\section{Nash equilibrium and competitive outcomes}

Note that each offer profile $w \in W$ induces a lottery over outcomes. Each outcome $\left(y,\left(-\widetilde{p}_{i} y_{i}\right)\right)$ is realized with probability $\mu_{w}(y)>0$ if $y \in F(w)$, and $\mu_{w}(y)=0$ if not. Given an offer profile $w \in W$, the expected utility for each trader is,

$$
E u_{i}(w)=\sum_{y \in F(w)} \mu_{w}(y) u_{i}\left(y_{i},-\widetilde{p}_{i} y_{i}\right)
$$


A (pure strategy) Nash equilibrium for an economy $r$ is an offer profile $w^{*} \in W$ such that for every $i \in I$,

$$
E u_{i}\left(w_{i}^{*}, w_{-i}^{*}\right) \geq E u_{i}\left(w_{i}^{\prime}, w_{-i}^{*}\right) \text { for all } w_{i}^{\prime} \in W_{i} .
$$

As in the market games studied by Dubey (1982), Simon (1984) and Benassy (1986), in this strategic market game, every competitive equilibrium outcome can be reached by with probability one by at least one Nash equilibrium offer profile, and all the positive probability outcomes of a Nash equilibrium are competitive as long as in the Nash equilibrium there are at least two active traders on each side of the market.

Theorem 1. For every competitive equilibrium, there is a Nash equilibrium that induces the same outcome with probability one.

To prove the theorem, we consider an offer profile such that each agent offers the trading price and quantity she obtains in the competitive equilibrium, and show that such offer profile is a Nash equilibrium and yields exactly the same outcome as in the competitive equilibrium. Agents have no incentive to deviate from the proposed offer profile: since the quantity offered in the profile is utility-maximizing given the competitive price, obtaining a different quantity at the same price does not increase the payoff for the individual; given other agents are offering the same price, increasing offer price as a seller or decreasing offer price as a buyer, regardless of the quantity offered, reduce the chance of trade to 0 , and thus cannot be payoff-improving; decreasing offer price as a seller or increasing offer price as a buyer reduces the payoff for sure as the new price is less preferred to the competitive price, even at its corresponding utility-maximizing quantity.

As long as condition (A) is satisfied (which is, of course, the case of interest), there are Nash equilibria that induce noncompetitive allocations. For instance, any offer profile such that $\widetilde{q}_{i}=0$ for all $i$, or such that $\min _{i \in S} \widetilde{p}_{i}>\max _{h \in B} r_{h 1}$ and $\max _{i \in B} \widetilde{p}_{i}<$ $\min _{h \in S} r_{h 1}$, is a Nash equilibrium. Those Nash equilibria result in no trade. We restrict our attention on Nash equilibria such that trade happens with positive probability, so that $A S(w)$ and $A B(w)$ are nonempty. We have

Theorem 2. In every Nash equilibrium with at least two active traders on each side, every positive probability outcome is competitive.

To prove theorem 2, we first show that in any given Nash equilibrium, all active traders offer the same price. Then we show that in every allocation induced by a Nash profile, the quantity that an active trader is allocated is utility-maximizing given the Nash price. The intuition is that if an active trader does not get the utility-maximizing quantity at the Nash price, the trader can always obtain a more preferable quantity by offering a slight lower or slightly larger price.

Note that there is a gap between the statement of theorem 2 and the no-trade examples preceding the statement of the theorem. Theorem 2 leaves open the possibility that there are Nash equilibria with active trading but with noncompetitive outcomes and in which there is only one active trader in at least one of the two sides of the market. In the proof of the theorem, we rely on two or more active sellers in order to show that there is no Nash equilibrium in which one seller produces less than the competitive allocation 
requires. Intuitively, these situations would correspond to the single active seller behaving as a monopolist and charging a price above the competitive level. Similarly, there could be situations in which there is a single active buyer behaving as a monopsonist and charging a price below the competitive level. Finally, there could be situations in which there is a single active buyer and a single active seller, and competitive outcomes are not reached even if the price is competitive because of a coordination failure: both the buyer and the seller offer suboptimal quantities. As a simple illustration, consider $S=\{1,2\}, B=\{3,4\}, k=2$, and $r_{11}=r_{12}=1, r_{31}=r_{32}=3, r_{21}=r_{22}=r_{41}=r_{42}=2$. The unique competitive equilibrium price is 2 ; all competitive equilibria involve trading two or more units, but there are Nash equilibria with only one unit traded, for instance $w_{1}=w_{3}=(2,1), w_{2}=w_{4}=(2,0)$.

In what follows, we provide necessary and sufficient conditions for all the outcomes of every Nash equilibrium with trade to be competitive. It is easy to check that if for a given economy there are competitive equilibria in which only one unit is traded, then all outcomes of every Nash equilibrium profile with trade are efficient. The reason is that if one unit is traded in a given outcome induced by an equilibrium profile, both the active buyer and the active seller must be offering the same price. If any buyer has a reservation price higher than the Nash price and is not trading, the buyer can offer a price that is slightly higher and grab the trade, so that in equilibrium the buyer who trades must be the one with the highest reservation price. A similar argument applies on the supply side. However, the trading price may not be competitive in the Nash equilibrium. A simple example is $S=\{1,2\}, B=\{3,4\}, k=2$, and $r_{11}=1, r_{12}=2$, $r_{21}=r_{22}=4, r_{31}=5, r_{32}=r_{41}=r_{42}=2$. The competitive price is 2 in this economy, and there is a competitive equilibrium in which seller 1 sells one unit to buyer 3 . A Nash equilibrium $w^{*}=((3,-1),(3,0),(3,1),(3,0))$ results in a trading price of 3 , which is not a competitive price, but the outcome is efficient.

From here on, we focus on economies such that all competitive equilibria involve trading two or more units, which is a more demanding condition than (A).

Define buyers' marginal value, $v_{b}$, as the maximum of the lowest reservation value for buyers' units traded in competitive equilibria, that is,

$$
v_{b}=\max _{(p, q) \in \xi(r)} \min _{q_{i}>0} r_{i, q_{i}} .
$$

Similarly, define the sellers' marginal value, $v_{s}$, as the minimum of the highest reservation value for sellers' units traded in competitive equilibria, that is,

$$
v_{s}=\min _{(p, q) \in \xi(r)} \max _{q_{i}<0} r_{i,\left|q_{i}\right|} .
$$

In economies such that (A) is satisfied, $v_{b}$ and $v_{s}$ are well-defined, since in every competitive equilibrium at least some $i^{\prime} \in S$ with the minimum cost (i.e. $r_{i^{\prime} 1}=\min _{i \in S} r_{i 1}$ ) must have $q_{i^{\prime}}<0$, and at least some $i^{\prime \prime} \in B$ with the maximum reservation value (i.e. $r_{i^{\prime \prime} 1}=\max _{i \in B} r_{i 1}$ ) must have $q_{i^{\prime \prime}}>0$. Moreover, if (A) is satisfied, we must have $v_{b}>v_{s}$, because if there is a competitive equilibrium such that both the marginal buyer and the marginal seller are indifferent (i.e. $\min _{q_{i}>0} r_{i, q_{i}}=p=\max _{q_{i}<0} r_{i,\left|q_{i}\right|}$ ), there is another competitive equilibrium in which one fewer unit is traded. 
Denote by $\bar{p}$ and $\underline{p}$ the highest and lowest competitive price respectively. It is easy to check that

$$
v_{s} \leq \underline{p} \leq \bar{p} \leq v_{b} .
$$

The first and third inequalities above follow from the fact that for every equilibrium $(p, q) \in \xi(r)$ we must have $\max _{q_{i}<0} r_{i,\left|q_{i}\right|} \leq p \leq \min _{q_{i}>0} r_{i, q_{i}}$.

We say that $i \in B$ is an intramarginal buyer if $r_{i 1} \geq v_{b}$. Similarly, we say that $i \in S$ is an intramarginal seller if $r_{i 1} \leq v_{s}$. Intuitively, an intramarginal trader is someone who is willing to trade at any equilibrium price. Note that in economies satisfying (A), there is at least one intramarginal trader in each side of the market, since every seller with the minimum cost and every buyer with the maximum reservation value is intramarginal.

We say that $i \in B$ is a weakly intramarginal buyer if $r_{i 1}>v_{s}$ and $r_{i 1} \geq p$. Similarly, we say that $i \in S$ is a weakly intramarginal seller if $r_{i 1}<v_{b}$ and $r_{i 1} \leq \bar{p}$. Intuitively, a weakly intramarginal trader is someone who would generate positive social surplus if matched in pairwise trade with an intramarginal trader on the other side of the market. Using $v_{b}>v_{s}$ and $v_{s} \leq p \leq \bar{p} \leq v_{b}$, it is easy to check that, in economies satisfying (A), all intramarginal traders are also weakly intramarginal (justifying our nomenclature).

We have

Theorem 3. In economies such that all competitive equilibria involve trading two or more units, every positive probability outcome from every Nash equilibrium with active trade is competitive if and only if there are at least two intramarginal traders on one side of the market, and at least two weakly intramarginal traders on the other side.

Intuitively, rivalry between two traders on the same side of the market who can exploit mutually advantageous trades with at least two traders on the other side of the market both eliminates monopoly and monopsony power and precludes coordination failures. In the coordination failure example proposed above, we have $v_{s}=1, v_{b}=3$, and all traders are weakly intramarginal but only one seller and one buyer are intramarginal.

The condition $r_{i 1} \geq p$ for $i \in B$ and $r_{i 1} \leq \bar{p}$ for $i \in S$ to be a weakly intramarginal trader ensures that the trader has a value "close enough" to the competitive range, so that the trader weakly prefers to trade in the competitive equilibrium. Without this condition, there may be noncompetitive Nash equilibrium outcomes. Consider the economy $S=\{1,2\}, B=\{3,4\}, k=3$, and $r_{11}=r_{21}=1, r_{12}=r_{13}=r_{22}=r_{23}=4$, $r_{31}=r_{32}=r_{33}=3, r_{41}=r_{42}=r_{43}=1$. Seller 1 , seller 2 , and buyer 3 are intramarginal traders, while buyer 4 satisfies one of the conditions to be weakly intramarginal but not $r_{i 1} \geq p$. Here buyer 4 strictly prefers not to trade in the competitive equilibrium, and the range for Nash equilibrium prices is [2,3], including prices that are not competitive.

It is worth noticing that theorem 3 includes the contestable market scenario (Baumol et al., 1982), in which there is only one active seller but all outcomes from Nash equilibria are competitive. An example is the economy $S=\{1,2\}, B=\{3,4\}, k=2$, and $r_{11}=r_{12}=r_{21}=r_{22}=2, r_{31}=4, r_{41}=3, r_{32}=r_{42}=1$. The competitive equilibrium price is 2 in this economy, and two units are traded in every competitive equilibrium. We have $v_{b}=3$ and $v_{s}=2$ for this economy, so all traders are intramarginal and the condition in theorem 3 holds. One of the Nash equilibria in this economy is $w=((2,-2),(2,0),(2,1),(2,1))$, in which seller 1 is the only active seller, but the 
outcome is competitive. The presence of seller 2 , a non-active seller in the Nash equilibrium, brings enough competition to the market to make the outcome competitive.

\section{Experimental design}

We test the predictive ability of our market game model in laboratory experiments. We consider two experimental markets with indivisible commodities. One is a competitive market, in which the condition in theorem 3 is satisfied, so that Nash equilibrium outcomes coincide with competitive equilibrium outcomes; and the other one is a monopolistic market, in which the condition in theorem 3 is not satisfied, so that some Nash equilibrium outcomes are non-competitive. By theorem 1, all competitive equilibrium outcomes are achievable by Nash equilibrium, even if not all Nash equilibrium outcomes are competitive. In the experiment, we test how well the Nash equilibrium of our model predicts individuals' behavior in both markets, and how likely are noncompetitive outcomes when Nash and competitive equilibrium outcomes do not coincide completely.

To make a straightforward comparison between the two markets, we have the same market demand and supply in both. Each market has two buyers $B=\{B 1, B 2\}$ and two sellers $S=\{S 1, S 2\}$, and each trader can wither buy or sell two units. Market supply and demand are shown in figure 2. Two units are traded in every competitive equilibrium. The competitive price range is $\$ 15-\$ 19$.

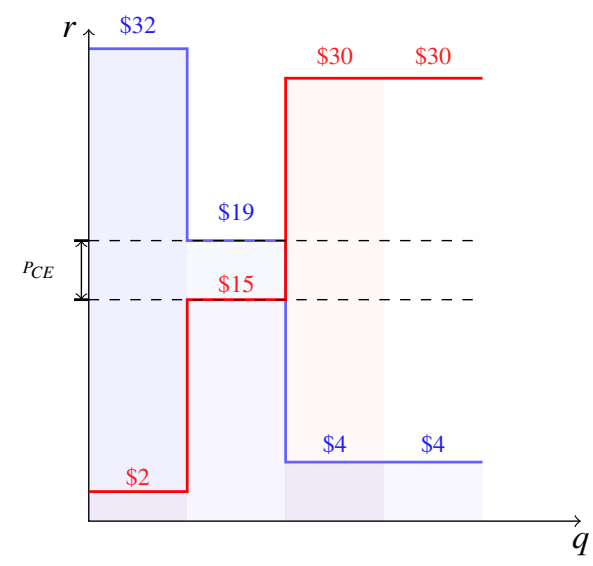

Figure 2: Supply and Demand

We assign the first and third highest demand reservation values to one buyer, and the second and fourth to the other buyer. By assigning the units to sellers in different ways, we create a market that satisfies the condition in theorem 3 , and a market that does not. In our competitive market, the two supply units that can be traded in competitive equilibrium are assigned each to each one of the two sellers. Thus, as shown in the left part of figure 3, there are two intramarginal traders on each side of the market. By theorem 3, Nash equilibrium outcomes with trading of the strategic market mechanism 
coincide with competitive equilibrium outcomes. In our monopoly market, instead, those two units are assigned to the same seller. Thus, as shown in the right part of figure 3, monopolistic outcomes could happen in Nash equilibrium. This design is similar to one implemented by Davis and Holt (1994).

In the competitive market, the price range for Nash equilibrium outcomes is the same as the competitive price range, $\$ 15-\$ 19$. In the monopolistic market, the price range for Nash equilibrium outcomes is instead \$15-\$30. Nash equilibrium outcomes in the monopolistic market include all the competitive outcomes, and also monopolistic outcomes where only one unit is traded at a price between $\$ 19$ and $\$ 30$.

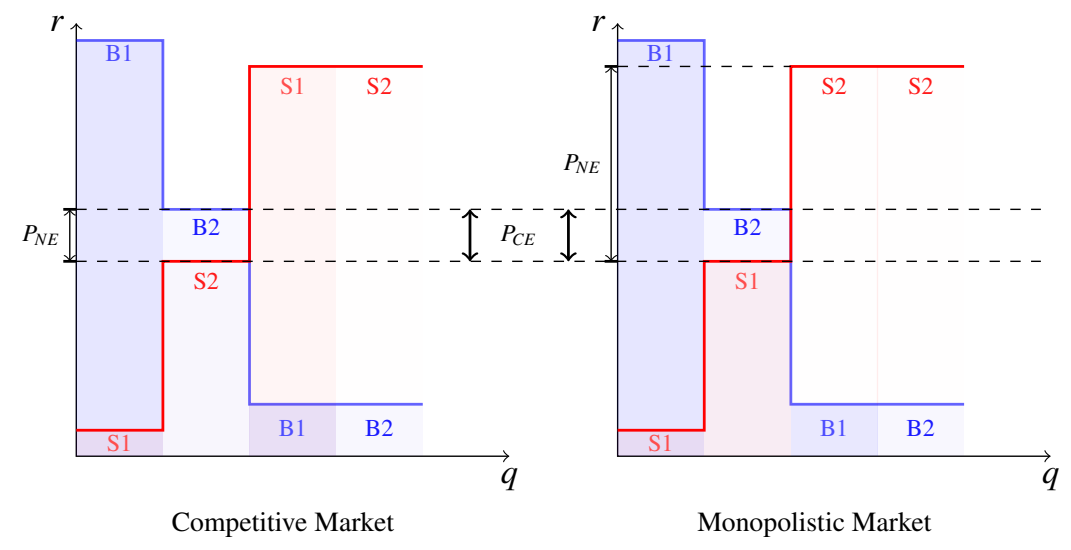

Figure 3: Competitive and Monopolistic Market

In the experiment, we compare the performance of the strategic market institution (Clearing House, or $\mathrm{CH}$ hereafter) with a continuous double auction (Double Auction, or DA hereafter) in two environments. The dynamic mechanism, DA, may aid learning, thus inducing faster convergence to equilibrium than the static mechanism, $\mathrm{CH}$.

In the clearing house institution, each trader submits a price-quantity pair to the clearing house. The clearing house then decides trade by the rules described in section 3, and reports the trader's own transaction price and quantity, together with the price and quantity traded in the market. We let $\mu_{w}(y)=1 /|F(w)|$ for all $y \in F(w)$ in the experiment; that is, the clearing house assigns equal probability to all arbitragemaximizing allocations. When making decisions, traders are given their own values, but not other traders' values or offers.

In the double auction institution, the traders buy/sell the good unit by unit. Each trader can submit limit offers for one unit, and each limit offer has to reduce the bidask spread to be valid. Valid offers are listed on the screen as public information for all traders in the market, with bids ranked from high to low and asks ranked from low to high. A transaction happens automatically if a valid bid is no lower than a valid ask. In each transaction, a bid will always be matched with the highest-ranked ask, and an ask will be traded with the highest-ranked valid bid. The trading price will be the price in the pair that was submitted later. After a trader has the first unit traded, he/she can submit limit offers for the second unit. All valid offers and transactions are shown in 
real time to all traders in the market.

The experiment was conducted in the Interdisciplinary Center for Economic Science (ICES) lab in George Mason University. In total, 240 subjects participated in the 18 sessions, and each session lasted for no more than 100 minutes. Each subject participated in only one treatment, playing the same role (B1, B2, S1 or S2) in the same market for 20 rounds. The final payoffs ranged from $\$ 5$ to $\$ 36$.

The experiment was computerized, and programmed in oTree (Chen et al., 2016). At the beginning of the session, the participants were seated at partitioned computer stations and allowed 10 minutes to read the instructions on their own. Then an experimenter read the instructions out loud to all participants. Afterward, a quiz was handed out, and the experiment began after each participant gave correct answers to all the questions in the quiz. Then the role a participant had in the experiment was revealed to him/her, and the participants were given a practice round before the formal rounds began. There were 20 formal rounds, one of which was randomly chosen for payment. After the 20 formal rounds, each participant was informed of the round chosen for payment and his/her own payoff. The payment was made privately.

\section{Results}

We give an overview first, followed by a more detailed investigation.

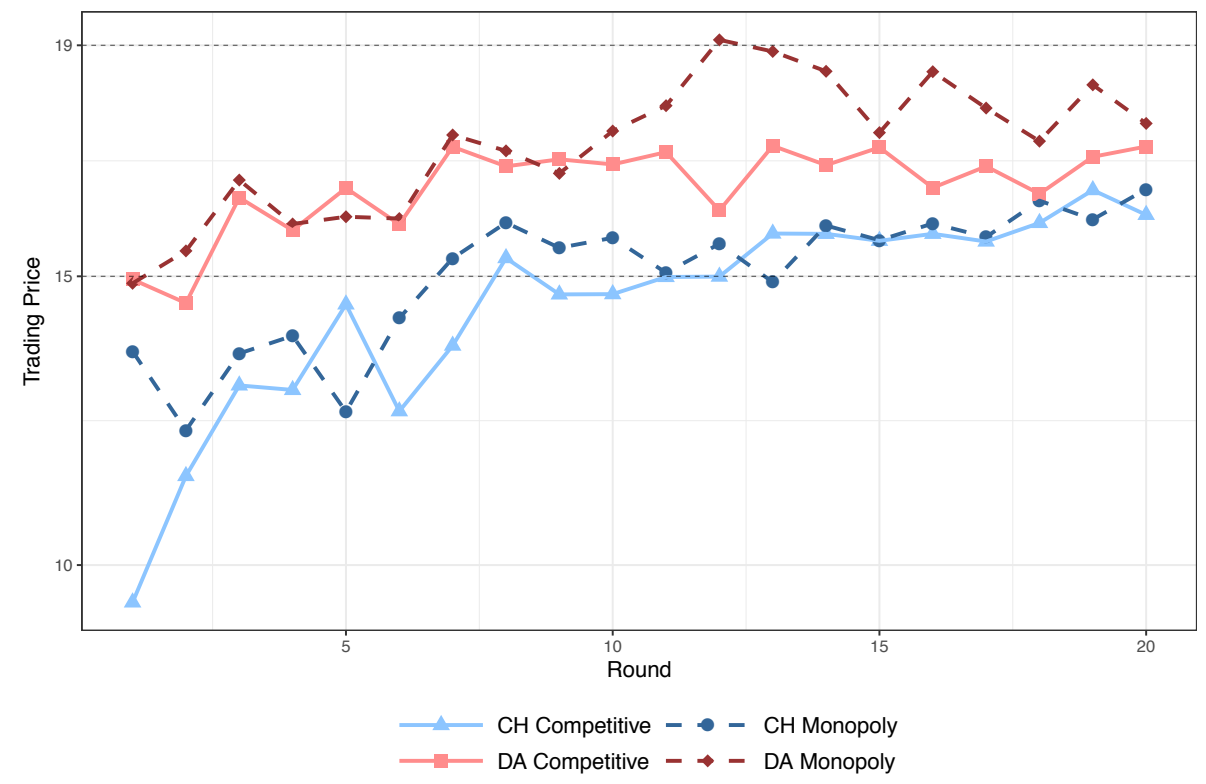

Figure 4: Average trading price over time. Red/blue lines correspond to clearing house/double auction. Solid/dashed lines correspond to competitive/monopolistic market. The thin horizontal lines are the boundaries of competitive price range. 
Figure 4 shows the average trading prices in each round in the four treatments. Two inferences can be drawn from figure 4, and they are supported by the statistics reported in table 1. First, the average prices adjust over time and stay in the competitive price range in the second half of the experiment in all treatments (average trading prices range from $\$ 15.73$ to $\$ 18.18$ ). The learning process takes longer under the clearing house institution: the average price starts low, and reaches the competitive range over time. The upward sloping trend is not as strong under the double auction institution: the average trading price starts within the competitive range. Second, compared to the competitive environment, the monopolistic environment brings forth a higher average trading price under the double auction institution, but not under the clearing house institution. Under the clearing house institution, there is no obvious difference in average trading prices when the market is monopolistic, especially when it comes to the second half of the experiment (one-sided Mann-Whitney $U$ test $p$-value $=0.95$ ). Under the double auction institution, after the first half of the experiment, the average trading prices go higher when the market is monopolistic (one-sided Mann-Whitney $\mathrm{U}$ test p-value $=4.03 \times 10^{-13}$ ).

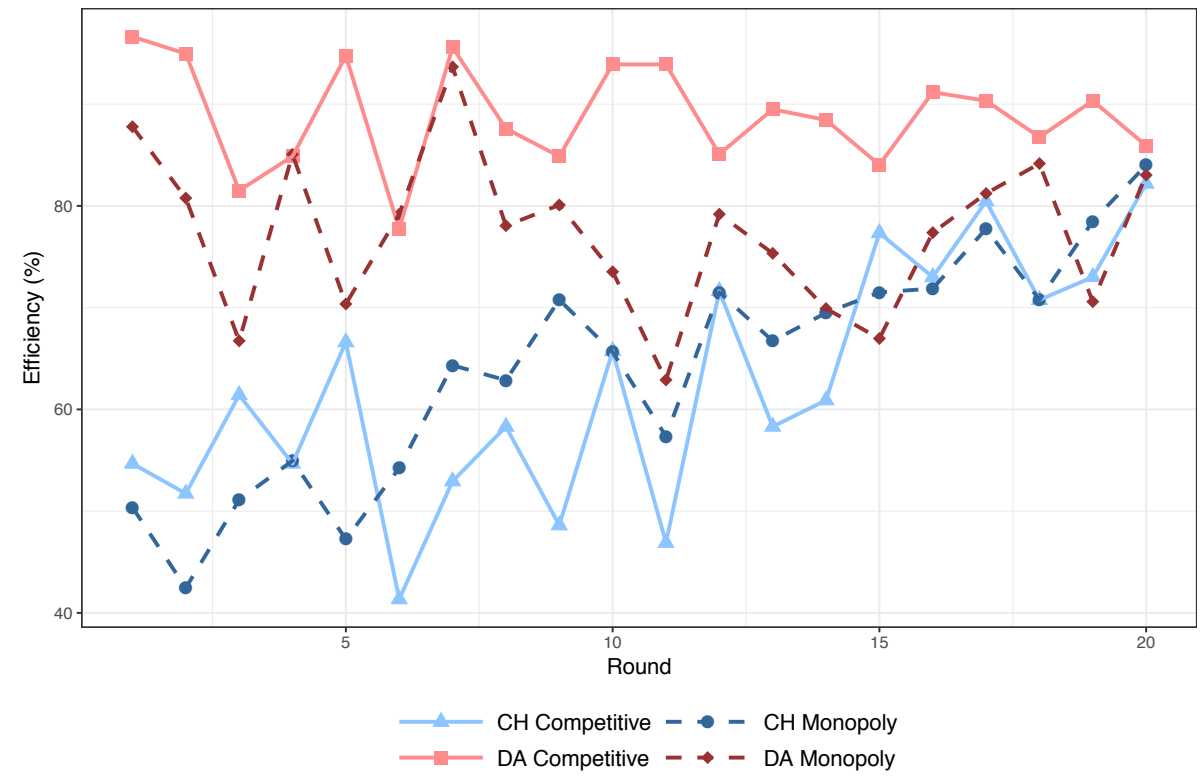

Figure 5: Average efficiency over time. Red/blue lines correspond to clearing house/double auction. Solid/dashed lines correspond to competitive/monopolistic market.

Figure 5 plots the average efficiency in each round in the four treatments. Efficiency is defined as the percentage of the maximum social surplus realized. Similar to what is shown in figure 4, learning takes longer under the clearing house institution; hence, average efficiency under the clearing house institution presents a stronger upward trend over time. Under the clearing house institution, the average efficiencies start at lev- 
els lower than under the double auction institution, and remain statistically lower in the second half of the experiment (one-sided Mann-Whitney U test p-value $=2.62 \times 10^{-12}$ for the competitive market and $\mathrm{p}$-value $=0.01$ for the monopolistic market). Nevertheless, we can observe from figure 4 that the upward trend of the efficiencies in clearing house treatments persist over time, and at the end of the experiment, the efficiency levels from the two institutions are close. Compared to the competitive environment, the monopolistic environment reduces the efficiency when the double auction institution is implemented (one-sided Mann-Whitney U test $\mathrm{p}$-value $=1.06 \times 10^{-8}$ ), but not so with the clearing house institution (one-sided Mann-Whitney $\mathrm{U}$ test p-value $=0.42$ ).

Overall, the average price and efficiency level show a tendency to converge to competitive equilibrium levels under both institutions when the market is competitive, and monopolistic pricing seems to occur more often under the double auction institution if a monopoly exists.

\begin{tabular}{|c|c|c|c|c|}
\hline & & & Trading Price & Efficiency (\%) ${ }^{\mathrm{a}}$ \\
\hline \multirow{4}{*}{ Mean values ${ }^{b}$} & CH Competitive & (17 markets) & $\begin{array}{l}15.73 \\
(2.70)\end{array}$ & $\begin{array}{c}69.45 \\
(32.39)\end{array}$ \\
\hline & CH Monopoly & (16 markets) & $\begin{array}{l}15.78 \\
(4.60)\end{array}$ & $\begin{array}{c}71.95 \\
(30.17)\end{array}$ \\
\hline & DA Competitive & (14 markets) & $\begin{array}{l}16.89 \\
(2.28)\end{array}$ & $\begin{array}{c}88.55 \\
(22.77)\end{array}$ \\
\hline & DA Monopoly & (13 markets) & $\begin{array}{l}18.18 \\
(5.41)\end{array}$ & $\begin{array}{c}75.07 \\
(33.57)\end{array}$ \\
\hline Kruskal-Wallis Test $^{c}$ & & & {$[150.16]^{* * *}$} & {$[72.55]^{* * *}$} \\
\hline \multirow{4}{*}{ Mann-Whitney U Test ${ }^{\mathrm{c}, \mathrm{d}}$} & Competitive vs & $\mathrm{CH}$ & $-[71145]$ & $+[13766]$ \\
\hline & Monopoly & DA & $-[46402]^{* * *}$ & $+[12429]^{* * *}$ \\
\hline & Clearing House vs & Competitive & $-[65379]^{* * *}$ & $-[6776.5]^{* * *}$ \\
\hline & Double Auction & Monopoly & $-[30299]^{* * *}$ & $-[8894.5]^{* *}$ \\
\hline
\end{tabular}

Note: Data includes only the last 10 rounds.

a Percentage of maximum social surplus realized. Efficiency = sellers' surplus + buyers' surplus + clearing house's profit.

${ }^{\mathrm{b}}$ Standard deviations in the parentheses.

c Test statistics in brackets.

$\mathrm{d}+$ and - signs indicate the alternative hypothesis being the first treatment in the comparison greater than the second treatment and the first smaller than the second respectively. $* * *, * *, *$ for significance levels of $1 \%, 5 \%$ and $10 \%$ respectively.

Table 1: Treatment effect

\subsection{Trading prices}

\subsubsection{Trend estimation}

To have a structural description of the price trend, we follow Noussair et al. (1995) and estimate

$$
p_{i t}=\alpha_{1} D_{1} \frac{1}{t}+\ldots+\alpha_{i} D_{i} \frac{1}{t}+\ldots+\beta \frac{t-1}{t}+\varepsilon_{i t}
$$

for each treatment, where $p_{i t}$ is the average price in market $i$ at round $t, D_{i}$ is an indicator for individual market, which equals 1 if the market is $i$ and 0 otherwise, $\beta$ is 
the asymptote for the average price in the treatment, and $\varepsilon_{i t}$ is an error term. By using this statistical model, we assume that although each market has its own pattern of convergence, there is a common asymptote by treatment.

Table 2 lists the estimated $\beta$ for each treatment, that is the estimated long-run average price in a market, together with their $95 \%$ confidence intervals. Table 7 with the full results of regressions is in the appendix. From the prediction of the regression, under the clearing house institution, there is no long-run trend toward monopolistic prices in the presence of a monopoly. However, under the double auction mechanism, the $95 \%$ confidence interval for the long run prices covers prices outside of the competitive price range, although within the range of Nash equilibrium prediction in our model. Therefore, as long as our regression is correctly specified, we can reach the conclusion that the clearing house institution generates more robustly competitive prices under different market structures.

\begin{tabular}{lcc}
\hline Treatment & $\hat{p}^{*}$ & 95\% Confidence Interval \\
\hline CH Competitive & 16.12 & {$[15.68,16.57]$} \\
CH Monopoly & 16.02 & {$[15.90,16.14]$} \\
DA Competitive & 16.98 & {$[16.65,17.32]$} \\
DA Monopoly & 19.20 & {$[18.51,19.90]$} \\
\hline
\end{tabular}

Note: We use feasible generalized least square estimation with $\mathrm{AR}(1)$ correction for the panel dataset, so both heteroscedasticity between markets and the autocorrelation within market can be treated.

Table 2: Average price asymptote by treatment

\subsubsection{Price distribution}

Since learning takes place in the earlier rounds, and we are more interested in the stationary state of the economy from this section to section 6.2, we use data from the second half of the experiment for the analyses. Figure 6 shows the distribution of trading prices in the last 10 rounds in different treatments. The DA Monopoly treatment has a heavy right tail outside of the competitive price range but within the Nash equilibrium range for that environment. In the $\mathrm{CH}$ Monopoly treatment, instead, most of the trading price within the Nash equilibrium range is also in the competitive price range. In both competitive treatments, trading prices cluster in the competitive price range. Except for the DA Competitive treatment, all treatments have a heavy left tail.

The heavy left tail in the clearing house house treatment could be the result of gradual learning given the static institution. Learning seems not be an important issue in the double auction treatment when the market is competitive. There is more price dispersion in monopoly environments. Some of the dispersion consists of upward deviations from the competitive range as predicted by Nash equilibrium, but downward deviations also happened in the monopolistic market under the double auction institution. Prices below the competitive equilibrium level were also observed by Smith and Williams (1990) in two monopolistic markets. One possible explanation is that there is more 


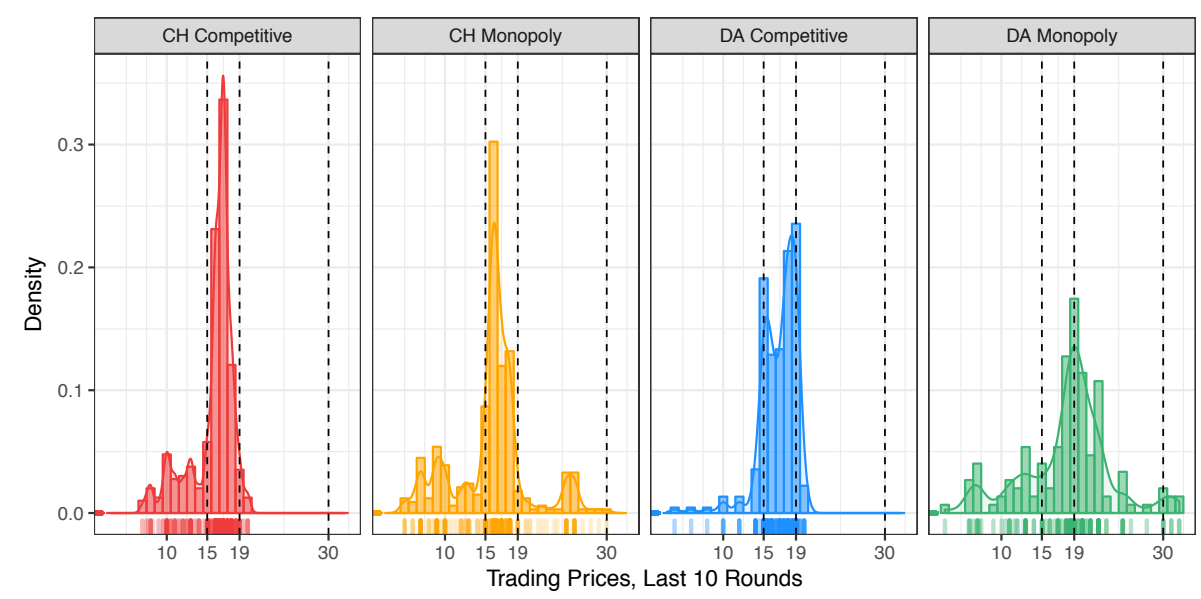

Figure 6: Distribution of trading prices

experimentation on possible trading prices when there are two rather than only one intramarginal seller. Thus, the monopoly seller did not learn about possible prices as well as sellers in the competitive environment, which could have been taken advantage of by buyers.

Figure 10,11, 12 and 13 in the appendix plot all the offers under $\$ 45$ in each treatment. The red shapes are trading prices. We can see price convergence over time in the graphs. Consistent with the discussion above, convergence to competitive levels was fastest in the DA Competitive treatment, in which the distribution of traded prices does not change much after very few rounds. Convergence happens slowly in the $\mathrm{CH}$ treatments, but also in the DA Monopoly treatment.

Results of previous double auction experiments indicate that prices tend to converge to the competitive level from a lower level if sellers obtain higher surplus than buyers at the competitive price, and vice versa (Holt, 1995). Our setting distributes equal market power to the buyers and sellers in the competitive environment, and consistent with previous studies, convergence of prices in the DA Competitive treatment seems unbiased to either side. However, under the clearing house institution, prices converge from a lower level to the competitive range, which could come from the anchoring effect of the instructions, where one digit numbers were used for demonstration to simplify calculations and facilitate understanding. The same set of numbers in the instructions did not have the same effect on DA treatment, which could be a consequence of faster learning in the dynamic mechanism.

\subsubsection{Predictive success index}

To explore whether Nash equilibrium is a good predictor for the experimental results, we use the predictive success index from Selten (1991). The predictive success index is the difference between the 'hit rate,' defined as the percentage of data that is coherent with the prediction of the model, and the 'area,' defined as the percentage of all possible 
outcomes that is coherent with the prediction of the model. The smaller the area, the more informative is the prediction made by the model. The index therefore takes into account both the accuracy and informativeness of the prediction.

Given that participants cannot submit a price that may cause a loss, the possible price range in our experiment is \$2-\$32. Thus, the area of the model is $13.33 \%$ for the competitive market and $50 \%$ for the monopolistic market. The predictive success indexes for Nash equilibrium are as follows:

$\begin{array}{llll}\text { CH Competitive } & 77.14 \%-13.33 \% & =63.81 \% \\ \text { CH Monopoly } & 76.35 \% & -50 \% & =26.35 \% \\ \text { DA Competitive } & 88.44 \% & -13.33 \% & =75.11 \% \\ \text { DA Monopoly } & 76.51 \% & -50 \% & =26.51 \%\end{array}$

The hit rates are not too different between treatments, but the model has higher predictive success for competitive markets than monopolistic markets, since the area of prediction is larger for the monopolistic market.

The range of competitive equilibrium prices lays within the range of Nash equilibrium prices in all treatments, and is equivalent to the range of Nash equilibrium prices in the competitive market. To see whether competitive equilibrium or Nash equilibrium has better predicting performance in monopolistic markets, we also calculate the predictive success index of the competitive equilibrium:

$$
\begin{array}{ll}
\text { CH Monopoly } 65.87 \%-13.33 \% & =52.54 \% \\
\text { DA Monopoly } & 39.60 \%-13.33 \%=26.27 \%
\end{array}
$$

In the monopolistic market under the clearing house institution, competitive equilibrium has higher predictive success than the Nash equilibrium, but both models have similar predictive success index under the double auction institution when the market is monopolistic. Under the clearing house institution, the majority of the trading prices that fall in the range of the Nash equilibrium are within the competitive price range $(86.27 \%$ of the trading price within the Nash equilibrium range are also within competitive range). Given the smaller range the competitive equilibrium predicts, competitive equilibrium has a better performance than Nash equilibrium. Under the double auction institution, trading prices within Nash equilibrium predictions are more evenly distributed among the competitive range and the non-competitive range, so the two models have similar predictive success. Therefore, the competitive equilibrium has a better predictive success when the clearing house institution is implemented, and similar (and low) predictive success as the Nash equilibrium when the double auction institution is implemented.

\subsection{Efficiency}

\subsubsection{Sources of inefficiency}

Inefficiency in the market comes in two ways: trading extramarginal units, or failing to trade intramarginal units. In our setting, the extramarginal units are the units with reservation values of 4 or 30 , which are not traded in any competitive equilibrium. 
As we can see in table 3 , there are very few trades that involve extramarginal units. None of the trades in $\mathrm{CH}$ Monopoly or DA Competitive treatments and less than 3\% of the trades in the other two treatments include extramarginal units. Hence trading extramarginal units is not an important source of inefficiency in our experiment.

\begin{tabular}{lcccc}
\hline & CH Competitive & CH Monopoly & DA Competitive & DA Monopoly \\
\hline Number of extramarginal trades & 3 & 0 & 0 & 4 \\
Number of trades & 199 & 167 & 225 & 149 \\
\hline Percentage of extramarginal trades & $1.51 \%$ & $0 \%$ & $0 \%$ & $2.68 \%$ \\
\hline Data
\end{tabular}

Data includes only the last 10 rounds.

Table 3: Extramarginal trade by treatment

Given that almost all trades include only intramarginal units, trading volume reflects intramarginal trading. Here we measure trading volume by the number of units traded over the number of intramarginal units, in percentage. In total two intramarginal units could be traded in each market. As figure 7 and table 4 show, the clearing house institution results in less trade than the double auction institution (one-sided Wilcoxon Mann U test p-value $=3.16 \times 10^{-11}$ for competitive markets and one-sided Wilcoxon Mann $\mathrm{U}$ test $\mathrm{p}$-value $=0.05$ for monopolistic markets), which is the main source of inefficiency in the clearing house institution.

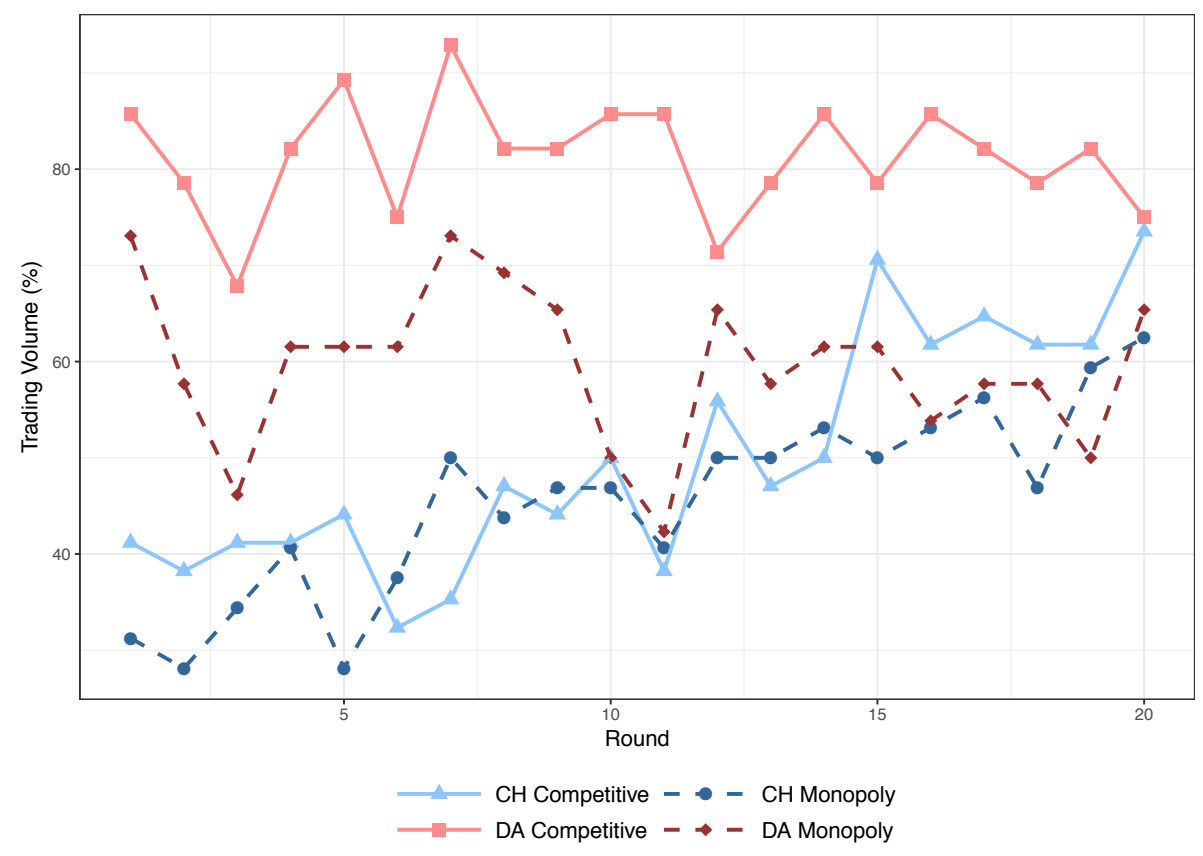

Figure 7: Average trading volume over time

The low trading volume in the clearing house institution could be a result of slower learning. Traders learn about possible trading prices through bargaining and observing, 
but bargaining is more costly in a static institution like the clearing house. Submitting offers favorable to themselves, traders risk losing the opportunity to trade in the round. Under the double auction institution, the negotiation can carry on until the time limit is reached, or one of the traders seizes the offer.

Figure 7 and table 4 illustrate that in the second half of the experiment, under both institutions, there are fewer trades in the monopolistic markets than in the competitive markets (one-sided Wilcoxon Mann U test $p$-value $=0.01$ for clearing house institution and one-sided Wilcoxon Mann $\mathrm{U}$ test $\mathrm{p}$-value $=8.86 \times 10^{-10}$ for double auction institution). Although monopoly suppliers under the clearing house institution were not able to charge monopolistic prices in average, trading volume is lower than in the competitive market.

\begin{tabular}{|c|c|c|c|c|}
\hline & CH Competitive & CH Monopoly & DA Competitive & DA Monopoly \\
\hline \multirow{2}{*}{ Trading Volume $(\%)^{\mathrm{a}}$} & 58.53 & 52.19 & 80.36 & 57.31 \\
\hline & $(28.80)$ & $(25.30)$ & $(26.62)$ & $(31.81)$ \\
\hline \multirow{2}{*}{ Sellers' Surplus (\%) ${ }^{\mathrm{b}}$} & 30.81 & 32.51 & 44.18 & 42.00 \\
\hline & $(17.62)$ & $(18.66)$ & $(15.08)$ & $(24.05)$ \\
\hline \multirow{2}{*}{ Buyers' Surplus (\%) ${ }^{\mathrm{b}}$} & 36.32 & 31.36 & 44.37 & 33.06 \\
\hline & $(21.33)$ & $(21.02)$ & $(15.88)$ & $(21.27)$ \\
\hline Number of Markets & 17 & 16 & 14 & 13 \\
\hline
\end{tabular}

Note: Standard deviations in the parentheses. Data includes only the last 10 rounds.

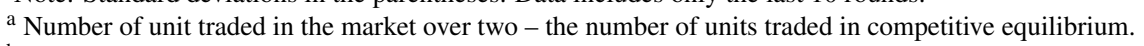

${ }^{\mathrm{b}}$ As a percentage of available total surplus in the market (Surplus/34).

Table 4: Mean values: trading volume and surplus

\subsubsection{Distribution of surplus}

A important issue in trading is the distribution of surplus. Demand and supply sides in our settings are symmetric, so neither of the sides has an advantage in the competitive environment. Mean values and standard deviations of buyers' and sellers' surplus can be found in table 4. Buyers' surplus and sellers' surplus are the total surplus for the two buyers and the two sellers respectively. In competitive environments, buyers get a higher average surplus than sellers when the clearing house institution is implemented, but the difference is not statistically significant (one-sided Wilcoxon Mann $U$ test pvalue $=0.45$ ). The surplus is split evenly by the two sides when the double auction institution is used, as expected from our symmetric setting.

The monopolistic environment decreases buyers' surplus in both institutions (onesided Wilcoxon Mann U test $\mathrm{p}$-value $=0.02$ for clearing house institution and onesided Wilcoxon Mann U test p-value $=3.99 \times 10^{-10}$ for double auction institution), but the monopoly does not get statistically significantly more than what the seller side can obtain in the competitive market (one-sided Wilcoxon Mann U test p-value $=0.48$ for clearing house institution and one-sided Wilcoxon Mann $U$ test $p$-value $=0.29$ for double auction institution). Thus, under neither institution the monopoly extracts more profit than competitive sellers, and nevertheless, buyers' surplus is reduced by insufficient competition on the sellers' side. 


\subsection{Additional results}

Our lab experiments involve the minimum number of traders using the double auction that we know of, which makes it a good robustness check for the properties of the double auction mechanism. Figure 8 compares the efficiency level in our double auction markets with a few double auction markets in previous studies (Smith et al., 1982; Smith, 1982; Smith and Williams, 1990; Kachelmeier and Shehata, 1992; Friedman and Ostroy, 1995; Kimbrough and Smyth, 2018). Double auction markets conducted in previous studies are mostly used for testing the robustness of the mechanism, so disturbances may have been introduced during the session, and different settings have been used in these studies. We can see that the efficiency in thicker markets is higher than in our four-trader market, although the difference is not large when markets are competitive.

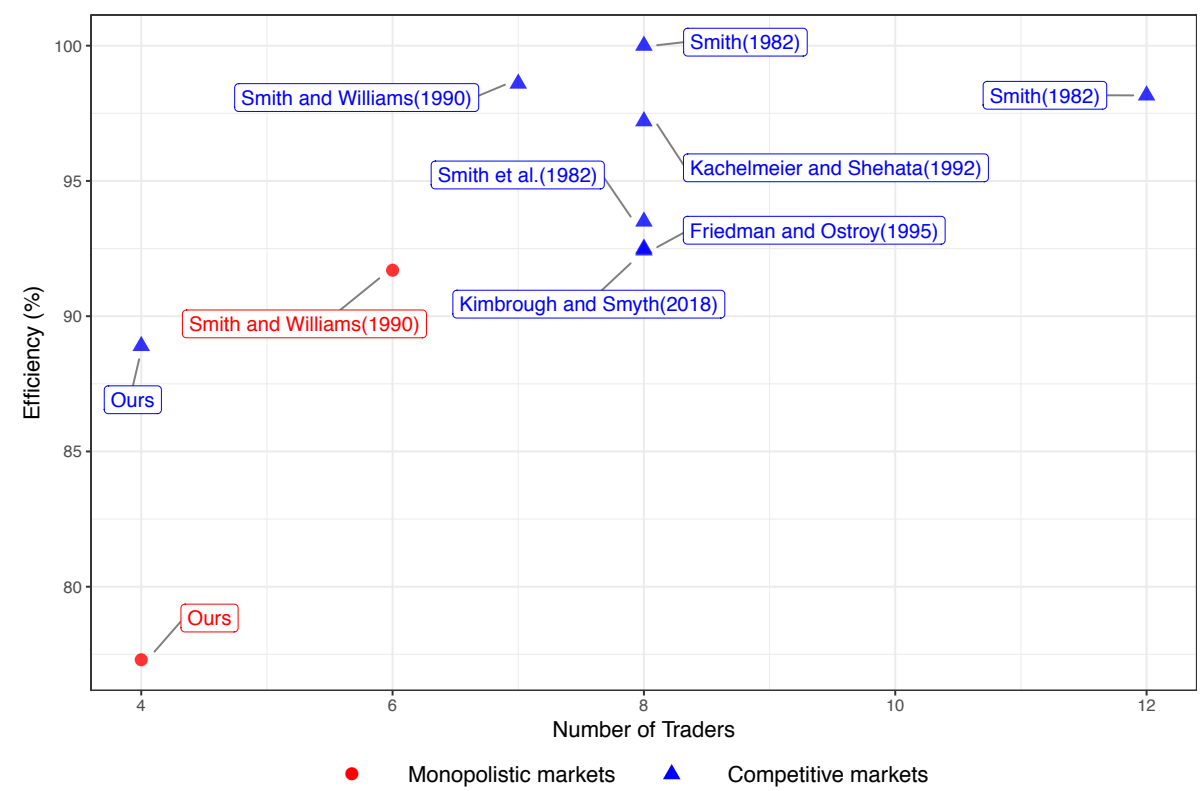

Figure 8: Efficiency and number of traders in the literature. All the points are average efficiency using all rounds.

As side results, we briefly tested our data for two issues raised by previous studies using the double auction institution.

\subsubsection{Marshallian path}

As described by Plott et al. (2013), the Marshallian path may be a force leading to competitive equilibrium allocations in a double auction market. The Marshallian path occurs when, even if early trade in the market happens at off-equilibrium prices, every traded unit is sold by the seller who has the lowest cost and bought by the buyer who 
has the highest value at the time of trade. Then, since the value-cost spread becomes smaller as trade happens, prices get closer to equilibrium levels over time. Cason and Friedman (1996) and Plott et al. (2013) confirmed the existence of a Marshallian path in the double auction experiment - trade that happens earlier tends to have a higher surplus.

We test the Spearman's rank correlation between transaction order ( 1 for the first transaction and 2 for the second) and surplus from trade, buyer's value, and seller's cost. According to the Marshallian path prediction, surplus from trade is higher, buyer's value is higher, and seller's cost is lower in the earlier transactions. The results from table 5 and table 6 are in line with this prediction, except that in the second half of the competitive market, buyers might have learned enough about equilibrium prices, and the effect of Marshallian path is no longer significant for buyer's value.

\begin{tabular}{lccc}
\hline & surplus from trade & . buyer's value & seller's cost \\
\hline DA Competitive & $-0.39^{* * *}$ & $-0.20^{* * *}$ & $0.36^{* * *}$ \\
DA Monopoly & $-0.75^{* * *}$ & $-0.36^{* * *}$ & $0.97^{* * *}$ \\
\hline
\end{tabular}

$* * *, * *, *$ for significance levels of $1 \%, 5 \%$ and $10 \%$ respectively. Data includes only the first 10 rounds.

Table 5: Spearman's rank correlation coefficient $(\rho)$ between transaction order and other variables (first 10 rounds)

\begin{tabular}{lccc}
\hline & surplus from trade & buyer's value & seller's cost \\
\hline DA Competitive & $-0.25^{* * *}$ & -0.10 & $0.23^{* * *}$ \\
DA Monopoly & $-0.76^{* * *}$ & $-0.49^{* * *}$ & $0.88^{* * *}$ \\
\hline
\end{tabular}

$* * *, * *, *$ for significance levels of $1 \%, 5 \%$ and $10 \%$ respectively. Data includes only the last 10 rounds.

Table 6: Spearman's rank correlation coefficient $(\rho)$ between transaction order and other variables (last 10 rounds)

Figure 9 shows counts of different reservation values of the units traded in the second half of the experiment. In the competitive environment, it is often the case that buyers with the highest reservation value do not trade first, seemingly contradicting the Marshallian path. A reason for this may be that in our experiment, participants played identical games, unlike Cason and Friedman (1996) and Plott et al. (2013) who randomized reservation values for each subject in each round. In our competitive treatments, the Marshallian path is in effect in the earlier rounds, but fades after the price is discovered. In the monopolistic environment, instead, it is transparent that the first transaction happens mostly between the highest value buyer and lowest value seller. The seller's part is trivial, since the monopoly has to sell the first unit before the second unit is offered. On the buyers' side, an explanation could be that, since fewer units were traded, buyers faced more competition, and the one with higher value risked more by 
not trading, so was more eager to accept the offer and trade earlier. Also, if the price went beyond 19, the buyer with lower reservation value could no longer trade.
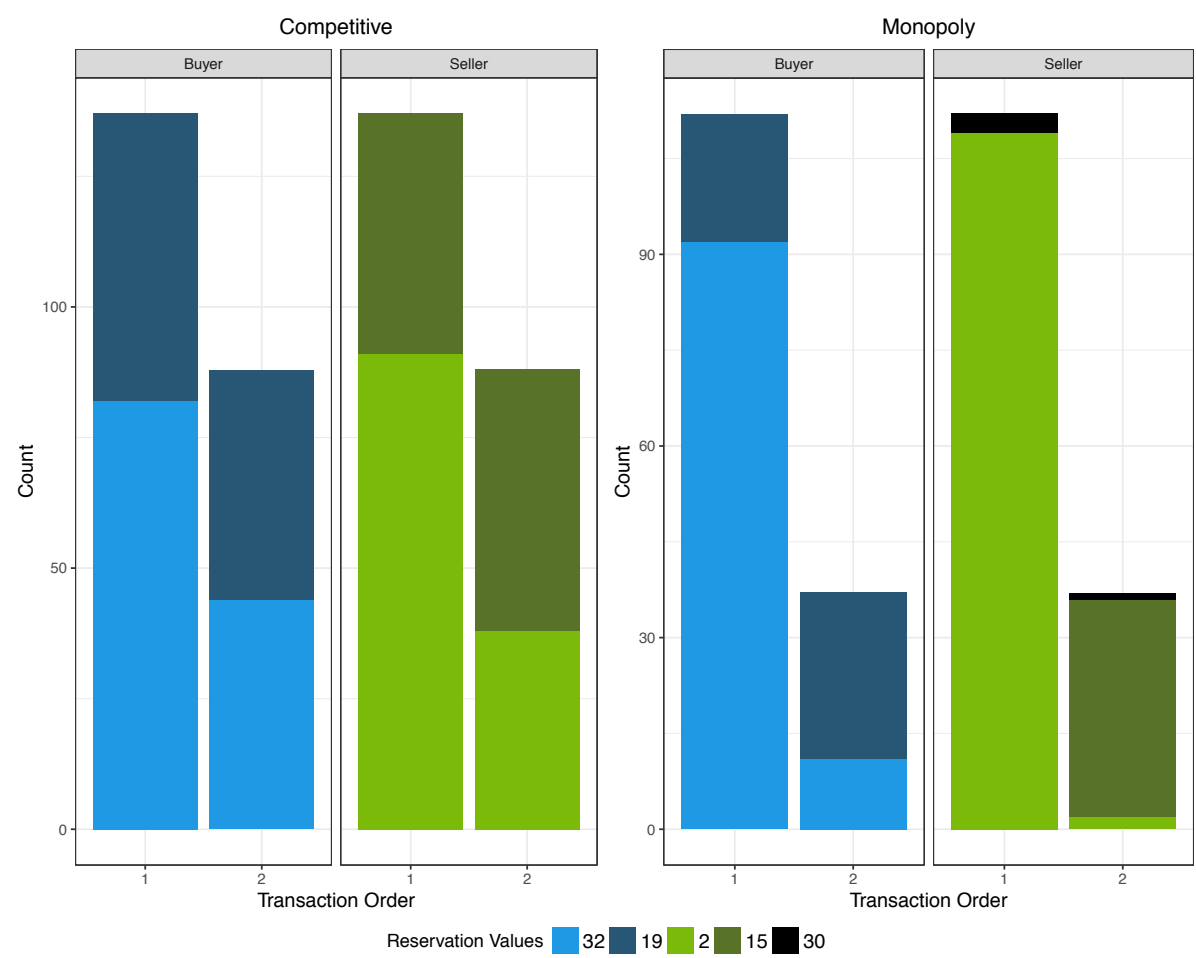

Figure 9: Transaction order for DA treatment, last 10 rounds. Colors indicate the reservation value of the traded unit.

\subsubsection{Coasian dynamics}

The monopoly under the double auction institution in our experiment faces the same problem as the durable goods monopoly in Coase (1972). After selling one unit at the monopoly price, it is in the monopolist seller's best interest to lower the price and sell another unit. Expecting this, patient buyers may withhold purchase until the price is at the competitive level. Nonetheless, the monopoly could have extracted a higher profit if committing to sell the monopoly quantity at the monopoly price. In our experiment, the monopoly cannot reduce the durability of the good or add other conditions in the contract as suggested by Coase (1972) to resolve this durable good problem. In particular, in the model of Coasian dynamics proposed by Cason and Sharma (2001), a monopoly sells durable goods to two buyers, each of whom has a privately known value for one unit, the price the monopoly charges will equal to the lowest value the buyers have, which is a competitive price, if the discount factor equals 1 as what we have in the experiment since our experiment is in continuous time. 
The monopoly ability to exercise market power varies in double auction markets in laboratory experiments (Smith, 1981; Smith and Williams, 1990). Porter (1991) pointed out that the static monopoly model does not predict the outcome in double auction well since it is hard for the monopoly to commit to the monopolistic price and quantity.

To see if Coasian dynamics is present in our data, we can check whether the second transaction price in a round is lower than the first one, and whether the monopoly sells more than one unit. The one-sided Mann-Whitney $U$ test for the first and second trading prices in the treatment has a p-value of $5 \%$, on the edge of rejecting the null hypothesis that trading prices are at the same level. The one-sided Wilcoxon signed rank test yields the p-value of 0.005 , rejecting the null hypothesis that the trading volume is $50 \%$ in the DA monopolistic market. Therefore, there is some evidence of Coasian dynamics in our double auction experiments.

\section{Conclusions}

In this paper, we propose a strategic market game for a market with money and an indivisible good, where buyers and sellers have both prices and quantities in their strategy space and trade via a profit-maximizing clearing house. We show that under a rather weak condition, two traders on each side of the market is enough to achieve only competitive outcomes in Nash equilibria with trade.

In our settings with indivisible good, the coincidence of Nash equilibrium and competitive equilibrium outcomes holds when there are at least two active buyers and two active sellers in the Nash equilibrium, as Dubey (1982), Simon (1984) and Benassy (1986) have for divisible good environments. This condition from previous studies does not apply to scenarios such as contestable markets, where there is only one active seller, but the threat of entry by another seller keeps the price at a competitive level. We provide a new sufficient and necessary condition for all outcomes from Nash equilibrium with active trading to be competitive, which includes the possibility that the Nash equilibrium has only one active seller, but has a competitive outcome. In line with Bertrand (1883), Dubey (1982), Simon (1984) and Benassy (1986), the condition requires as few as two potentially active traders on each side of the market to guarantee competitive outcomes in Nash equilibria.

We test our theoretic results in laboratory experiments. There are two buyers and two sellers in the market, each of whom can trade up to two units. By assigning units of different values to the two sellers in different ways, we induce two market environments-one satisfies the necessary and sufficient condition for all Nash equilibrium outcomes to be competitive, while the other one is a monopolistic market and allows for competitive and monopolistic outcomes in Nash equilibrium. The performance of sealed-bid auction, following the rules of the strategic market game, is compared to a continuous double auction, its dynamic counterpart.

When the sufficient and necessary condition is met, trading prices in both institutions converge to the competitive level, and the double auction achieves higher efficiency than the sealed-bid auction. We interpret the advantage of the double auction as a result of better opportunities for learning. Nevertheless, the efficiency of the 
sealed-bid auction increases over time and gets closer to the double auction institution as traders in the market gradually learn. The approximation to equilibrium outcomes is obtained without traders' knowledge of others' values under both institutions. Our results provide supportive evidence for the Hayek hypothesis (Hayek, 1945; Smith, 1982) in a limit setting with few traders: using appropriate institutions, markets can work with very limited information. Under the static institution, transaction prices are the only information revealed to each trader other than his/her own value. This information appears to be sufficient for achieving equilibrium outcomes, although it may take a few trials.

The efficiency loss from the existence of a monopoly is lower in the static institution. In the presence of a monopoly, most trading prices under the static institution remain in the competitive range, and buyers obtain less profit due to the reduction of trading volume while the total surplus in the market is not statistically significantly lower than the competitive market. Despite the effect of Coasian dynamics, the existence of monopolistic opportunity reduces the overall efficiency in the market when a double auction mechanism is used: in the monopolistic market, the trading price is higher and the trading volume is lower than in the competitive market. The predictive success of Nash equilibrium is lower in monopolistic environments-learning enough to behave as if possessing complete information is seemingly much harder in monopolistic than in competitive markets.

\section{Appendix A. Proofs}

\section{Characteristics of $F(w)$}

The following propositions provide some characteristics of $F(w)$ that are useful for later analysis.

Proposition 1. For any $y \in F(w)$, if $y_{b}>0$ and $y_{s}<0$ for a buyer $b$ and a seller $s$, then $\widetilde{p}_{b} \geq \widetilde{p}_{s}$.

Proof. Suppose $\widetilde{p}_{b}<\widetilde{p}_{s}$. Consider an alternative allocation $y^{\prime}$ such that $y_{i}^{\prime}=y_{i}$ if $i \neq b, s$ and $y_{b}^{\prime}=y_{b}-1, y_{s}^{\prime}=y_{s}+1$. Since $y \in F(w) \subseteq Y(w)$, we have $y^{\prime} \in Y(w)$, and

$$
\sum_{i \in I} y_{i}^{\prime} \widetilde{p}_{i}=\sum_{i \in I} y_{i} \widetilde{p}_{i}+\left(\widetilde{p}_{s}-\widetilde{p}_{b}\right)>\sum_{i \in I} y_{i} \widetilde{p}_{i}
$$

Then $y \notin F(w)$, contradicting the assumption.

Proposition 1 says that, for every implemented allocation, prices paid by buyers cannot be lower than prices paid by sellers-otherwise the clearing house would not maximize arbitrage profit. If the price offered by some buyer $b$ is lower than the price offered by some seller $s$, and in one allocation both buyer $b$ and seller $s$ make some trade, then the clearing house could have made more profit by letting both seller $s$ and buyer $b$ trade one less unit. Later in this appendix, we offer proposition 4 as a stronger version of proposition 1 .

By proposition 2, the clearing house buys all the units that can be sold at a higher or equal price. 
Proposition 2. Given an offer profile $w$ and a buyer $b$ and a seller $s$ such that $\widetilde{p}_{b} \geq \widetilde{p}_{s}$, there cannot be an allocation $y \in F(w)$ such that $y_{b}<\widetilde{q_{b}}$ and $y_{s}>\widetilde{q}_{s}$.

Proof. For a given offer profile $w$ such that there is a buyer $b$ and a seller $s$ that $\widetilde{p}_{b} \geq \widetilde{p}_{s}$, suppose there is an allocation vector $y \in Y(w)$ such that $y_{b}<\widetilde{q_{b}}$ and $y_{s}>\widetilde{q}_{s}$. We can show that $y \notin F(w)$. Take an alternative allocation vector $y^{\prime}$, let $y_{i}^{\prime}=y_{i}$ if $i \neq b, s$, and $y_{b}^{\prime}=y_{b}+1, y_{s}^{\prime}=y_{s}-1$. We have $y^{\prime} \in Y(w)$. The arbitrage profit for the clearinghouse by allocating $y^{\prime}$ is

$$
\sum_{i \in I} y_{i}^{\prime} \widetilde{p}_{i}=\sum_{i \in I} y_{i} \widetilde{p}_{i}+\left(\widetilde{p}_{b}-\widetilde{p}_{s}\right) \geq \sum_{i \in I} y_{i} \widetilde{p}_{i},
$$

where the last term is the clearing house's profit if it allocates $y$. Therefore, if $\widetilde{p}_{b}>\widetilde{p}_{s}$, then $\sum_{i \in I} y_{i} \widetilde{p}_{i}<\sum_{i \in I} y_{i}^{\prime} \widetilde{p}_{i}$ and $y \notin \Pi(w)$; and if $\widetilde{p}_{b}=\widetilde{p}_{s}$, then $\sum_{i \in I} y_{i} \widetilde{p}_{i}=\sum_{i \in I} y_{i}^{\prime} \widetilde{p}_{i}$ but $y$ is ray dominated by $y^{\prime}$. Either way we have $y \notin F(w)$.

An interpretation of proposition 2 is that, as long as a buyer's price is no lower than a seller's price, the two agents can trade until the quantity offered by one side is exhausted. When buyer $b$ offers a price higher than seller $s$, an allocation that does not acquire all units of at least one of the two would not maximize profits. When buyer $b$ offers the same price as seller $s$, an allocation that does not allocate all units of at least one of the traders offers would be ray-dominated by another allocation. We use this proposition frequently in the proofs of the theorems.

The next proposition shows that if two sellers offer different prices, the seller who offers the lower price has a priority to sell. Analogously, if two buyers offer different prices, the buyer who offers the higher price has a priority to buy.

Proposition 3. If, for a given offer profile $w$, seller $a$ and seller $b$ offer $\widetilde{p}_{a}<\widetilde{p}_{b}$, and seller $b$ is an active trader, then for all $y \in F(w)$ we have $y_{a}=\widetilde{q}_{a}$. Symmetrically, if in a given offer profile $w$, buyer $a$ and buyer $b$ offer $\widetilde{p}_{a}>\widetilde{p}_{b}$, and buyer $b$ is an active trader, then for all $y \in F(w)$ we have $y_{a}=\widetilde{q}_{a}$.

Proof. We will show the proof for the sellers' case, since the buyers' case is symmetric. By definition, if seller $b$ is an active trader, there exists an allocation $y^{*} \in F(w)$ such that $y_{b}^{*}<0$. First we show that $y_{a}^{*}=\widetilde{q}_{a}$.

Suppose $y_{a}^{*}>\widetilde{q_{a}}$. Take an alternative allocation vector $y^{\prime}$ given by $y_{a}^{\prime}=y_{a}^{*}-1$, $y_{b}^{\prime}=y_{b}^{*}+1$, and $y_{i}^{\prime}=y_{i}^{*}$ for $i \neq a, b$. It is easy to see that $y^{\prime} \in Y(w)$. The profit for the clearing house by allocating $y^{\prime}$ equals

$$
\sum_{i \in I} y_{i}^{\prime} \widetilde{p}_{i}=\sum_{i \in I} y_{i}^{*} \widetilde{p}_{i}+\left(\widetilde{p}_{b}-\widetilde{p}_{a}\right)>\sum_{i \in I} y_{i}^{*} \widetilde{p}_{i} .
$$

The last term is the profit of the clearing house if $y^{*}$ is allocated. Hence $y^{*} \notin \Pi(w)$, so $y^{*} \notin F(w)$. Therefore, if $y_{b}^{*}<0$ and $y^{*} \in F(w)$, we must have $y_{a}^{*}=\widetilde{q}_{a}$. By the same argument, we must have $y_{a}=\widetilde{q}_{a}$ for every allocation $y \in F(w)$ such that $y_{b}<0$.

Now suppose there is an allocation $\hat{y} \in F(w)$ such that $\hat{y}_{b}=0$ and $\hat{y}_{a}>\widetilde{q}_{a}$. According to the result in the first part of the proof, for any seller $h$ that offers $\widetilde{p}_{h}>\widetilde{p}_{a}, \hat{y}_{h}=0$, otherwise $\hat{y} \notin F(w)$. Hence

$$
\sum_{\left\{h \in S: \widetilde{p}_{h}>\widetilde{p}_{a}\right\}} \hat{y}_{h}=0>y_{b}^{*} \geq \sum_{\left\{h \in S: \widetilde{p}_{h}>\widetilde{p}_{a}\right\}} y_{h}^{*} .
$$


According to the first part of the proof, $y_{i}^{*}=\widetilde{q}_{i}$ for $i \in S$ if $\widetilde{p}_{i}<\widetilde{p}_{b}$. Since $\widetilde{p}_{b}>\widetilde{p}_{a}$, we have

$$
\sum_{\left\{h \in S: \widetilde{p}_{h} \leq \widetilde{p}_{a}\right\}} \hat{y}_{h} \geq \sum_{\left\{h \in S: \widetilde{p}_{h} \leq \widetilde{p}_{a}\right\}} \widetilde{q}_{h}=\sum_{\left\{h \in S: \widetilde{p}_{h} \leq \widetilde{p}_{a}\right\}} y_{h}^{*} .
$$

Therefore,

$$
\sum_{i \in B} y_{i}^{*}=-\sum_{i \in S} y_{i}^{*}>-\sum_{i \in S} \hat{y}_{i}=\sum_{i \in B} \hat{y}_{i}
$$

Since $\sum_{i \in B} \hat{y}_{i}<\sum_{i \in B} y_{i}^{*}$, there exists at least one buyer, say buyer $e$, such that $0 \leq$ $\hat{y}_{e}<y_{e}^{*} \leq \widetilde{q}_{e}$. Since $y_{e}^{*}>0$ and $y_{a}^{*}<0$, from proposition 1 we have $\widetilde{p}_{e} \geq \widetilde{p}_{a}$. Therefore $\widetilde{p}_{e} \geq p_{a}, \hat{y}_{a}>\widetilde{q}_{a}$, and $\hat{y}_{e}<\widetilde{q}_{e}$, violating proposition 2 .

Proposition 3 adapts the price priority condition of Benassy (1986). To maximize profit, the clearing house always prefers to buy from the seller who offers the lowest price, and only after it buys up all the units from this seller it starts buying from sellers who offers higher prices. Similarly on the buyer's side, the clearing house prefers to sell to the buyer who offers the highest price, and sells to lower price buyers if the former have no more units to buy.

Using proposition 2 and 3, we can get a more general version of proposition 1. By proposition 4, any price that active buyers pay is no lower than any price that active seller receive.

Proposition 4. Given an offer profile $w$, if buyer $b \in A B(w)$ and seller $s \in A S(w)$, then $\widetilde{p}_{b} \geq \widetilde{p}_{s}$.

Proof. Since $b \in A B(w)$ and $s \in A S(w)$, there must be some $y, y^{\prime} \in F(w)$ such that $y_{b}>0$ and $y_{s}^{\prime}<0$. If $y=y^{\prime}$, the desired result follows from Proposition 1. Suppose $y \neq y^{\prime}$. Since $y, y^{\prime} \in \Pi(w)$, we have

$$
\sum_{i \in A B(w)} y_{i} \widetilde{p}_{i}+\sum_{i \in A S(w)} y_{i} \widetilde{p}_{i}=\sum_{i \in A B(w)} y_{i}^{\prime} \widetilde{p}_{i}+\sum_{i \in A S(w)} y_{i}^{\prime} \widetilde{p}_{i}
$$

Suppose $\widetilde{p}_{b}<\widetilde{p}_{s}$. From Proposition 1 , we have $y_{s}=0$ and $y_{b}^{\prime}=0$. From proposition 3 , then, there is no active seller submitting a price higher than $p_{s}$, and no active buyer submitting a price lower than $p_{b}$. Denote by $\overline{A B}$ the set of active buyers that offer $p_{b}$, and $\underline{A S}$ the set of active sellers that offer $p_{s}$. From proposition 3, for $i \in A B(w) \backslash \overline{A B}$ and $i \in \overline{A S}(w) \backslash \underline{A S}$,

$$
y_{i}^{\prime}=y_{i}=\widetilde{q}_{i}
$$

Thus,

$$
\sum_{i \in \overline{A B}} y_{i} p_{b}+\sum_{i \in \underline{A S}} y_{i} p_{s}=\sum_{i \in \overline{A B}} y_{i}^{\prime} p_{b}+\sum_{i \in \underline{A S}} y_{i}^{\prime} p_{s},
$$

which is equivalent to

$$
p_{b} \cdot\left(\sum_{i \in \overline{A B}} y_{i}-\sum_{i \in \overline{A B}} y_{i}^{\prime}\right)=p_{s} \cdot\left(\sum_{i \in \underline{A S}} y_{i}^{\prime}-\sum_{i \in \underline{A S}} y_{i}\right) .
$$


Given $\widetilde{p}_{b}<\widetilde{p}_{s}$, the equation above implies either

$$
\sum_{i \in \overline{A B}} y_{i}-\sum_{i \in \overline{A B}} y_{i}^{\prime}=\sum_{i \in \underline{A S}} y_{i}^{\prime}-\sum_{i \in \underline{A S}} y_{i}=0
$$

or

$$
\sum_{i \in \overline{A B}} y_{i}-\sum_{i \in \overline{A B}} y_{i}^{\prime}>\sum_{i \in \underline{A S}} y_{i}^{\prime}-\sum_{i \in \underline{A S}} y_{i}
$$

Since $y_{b}>0$, in the first case there must be some buyer $c$ such that $y_{c}^{\prime}>0$ and $\widetilde{p}_{c}=\widetilde{p}_{b}<\widetilde{p}_{s}$. But since $y_{s}^{\prime}<0$, proposition 1 implies $\widetilde{p}_{c} \geq \widetilde{p}_{s}$, a contradiction.

In the second case we have

$$
\sum_{i \in \overline{A B}} y_{i}+\sum_{i \in \underline{A S}} y_{i}>\sum_{i \in \underline{A S}} y_{i}^{\prime}+\sum_{i \in \overline{A B}} y_{i}^{\prime},
$$

which implies

$$
\sum_{i \in I} y_{i}>\sum_{i \in I} y_{i}^{\prime}
$$

But since $y, y^{\prime} \in F(w) \subseteq Y(w)$, we have $\sum_{i \in I} y_{i}=\sum_{i \in I} y_{i}^{\prime}=0$, a contradiction.

Proposition 1 states that in each allocation in $F(w)$, any price the buyers pay is no lower than any price the sellers receive. Proposition 4 states that this result holds even when comparing across the allocations in $F(w)$. To prove this proposition, we can show that if the price a buyer pays in allocations $y \in F(w)$ is lower than the price a seller gets in allocation $y^{\prime} \in F(w)$, both $y, y^{\prime}$ cannot be in $F(w)$, otherwise one of the previous propositions would be contradicted.

The next proposition says that if some traders can only have part of their offers fulfilled, these traders must be on the same side of the market. The proposition is intuitive. Only if there are more units demanded than supplied, or the opposite, will there be rationing, so rationing happens to the side of the market that offers excess.

Proposition 5. If $y \in F(w)$, then either $y_{i}=\widetilde{q}_{i}$ for all $i \in A S(w)$ or $y_{i}=\widetilde{q}_{i}$ for all $i \in A B(w)$. Furthermore, if there is $y^{*} \in F(w)$ such that $y_{i}^{*}=\widetilde{q}_{i}$ for all $i \in A S(w)$, then $y_{i}=\widetilde{q}_{i}$ for all $y \in F(w)$ for all $i \in A S(w)$. Symmetrically, if there is $y^{*} \in F(w)$ such that $y_{i}^{*}=\widetilde{q}_{i}$ for all $i \in A B(w)$, then $y_{i}=\widetilde{q}_{i}$ for all $y \in F(w)$ for all $i \in A B(w)$.

Proof. For the first part, from proposition 4 , if buyer $b$ and seller $s$ are active, we have $p_{b} \geq p_{s}$. Thus, from proposition 2, there is no $y \in F(w)$ such that $y_{s}>\widetilde{q}_{s}$ and $y_{b}<\widetilde{q}_{b}$. Therefore, for every $y \in F(w)$, either $y_{i}=\widetilde{q}_{i}$ for all $i \in A S(w)$, or $y_{i}=\widetilde{q}_{i}$ for all $i \in A B(w)$.

For the second part, we show the proof for the active sellers' case, since the buyers' case is symmetric. Suppose there is $y^{*} \in F(w)$ such that $y_{i}^{*}=\widetilde{q}_{i}$ for all $i \in A S(w)$, and $y^{\prime} \in F(w)$ such that $y_{a}^{\prime}>\widetilde{q}_{a}$ for some $a \in A S(w)$. Then

$$
\sum_{i \in B} y_{i}^{*}=-\sum_{i \in S} y_{i}^{*}>-\sum_{i \in S} y_{i}^{\prime}=\sum_{i \in B} y_{i}^{\prime} .
$$

Therefore there must be an active buyer, say $b$, such that $y_{b}^{\prime}<y_{b}^{*} \leq \widetilde{q}_{b}$. From proposition 4 , we have $\widetilde{p}_{b} \geq \widetilde{p}_{a}$. But, from proposition $2, y_{a}^{\prime}>\widetilde{q}_{q}$ and $y_{b}^{\prime}<\widetilde{q}_{b}$ imply $\widetilde{p}_{b}<\widetilde{p}_{a}$, a contradiction. 
Finally, proposition 6 establishes that if two traders in the same side of the market offer the same price, then either both of them are active, or neither one. This proposition also shows that when allocating trade, the clearing house only differentiates traders by the prices they offer. The proof is done by showing that as long as seller $a$ is active, there exists an allocation vector in $F(w)$ such that seller $b$ sells a non-zero quantity.

Proposition 6. If seller a offers $\left(p, \widetilde{q}_{a}\right)$ in offer profile $w$ and $a \in A S(w)$, then seller $b$ who offers $\left(p, \widetilde{q}_{b}\right)$ where $\widetilde{q}_{b}<0$ is also an active seller. Symmetrically, if buyer a offers $\left(p, \widetilde{q}_{a}\right)$ in strategy profile $w$ and $a \in A B(w)$, then buyer $b$ who offers $\left(p, \widetilde{q}_{b}\right)$ where $\widetilde{q}_{b}>0$ is also an active buyer.

Proof. We show the proof for the sellers' case, since the buyers' case is symmetric. Suppose $y_{b}=0$ for all $F(w)$. Provided seller $a$ is an active seller, there exists $y \in F(w)$ such that $y_{a}>0$. Consider an allocation vector $y^{\prime}$ that $y_{i}^{\prime}=y_{i}$ for $i \neq a, b$ and $y_{a}^{\prime}=y_{a}-1$, $y_{b}^{\prime}=1$. It's easy to see that $y^{\prime} \in Y(w)$. The profit for the clearing house if $y^{\prime}$ is allocated is equal to

$$
\sum_{i \in I} y_{i}^{\prime} \widetilde{p}_{i}=\sum_{i \in I} y_{i} \widetilde{p}_{i}+p-p=\sum_{i \in I} y_{i} \widetilde{p}_{i}
$$

so that $y^{\prime} \in \Pi(w)$. Thus, either $y^{\prime} \in F(w)$ or there is $y^{\prime \prime} \in F(w)$ such that $y^{\prime \prime} \neq y^{\prime}$ and $\left|y_{i}^{\prime \prime}\right| \geq\left|y_{i}^{\prime}\right|$ for all $i$, so that in either case $b$ is an active trader, contradicting the assumption. Therefore, as long as seller $a$ is an active seller, so is seller $b$.

\section{Proof of Theorem 1}

Suppose $(p, q)$ is a competitive equilibrium. First we claim that the offer profile $w=$ $\left(\left(p, q_{i}\right)\right)$ induces the same outcome with probability one. To see this, since $\widetilde{p}_{i}=p$ for all $i$, the arbitrage profit for the clearing house is 0 for each $y \in Y(w)$, so that $\Pi(w)=Y(w)$. Clearly $q \in Y(w)$ since by definition of a competitive equilibrium $q_{i} \in Q_{i}$ and $\sum_{i} q_{i}=0$. Moreover, by definition of $Y(w)$, for every $y \in Y(w)$ we have $\left|y_{i}\right| \leq\left|q_{i}\right|$. Hence $q$ raydominates any other allocation in $\Pi(w)$ and is the unique element of $F(w)$. Thus, $w$ induces the outcome $\left(q,\left(-p q_{i}\right)\right)$ with probability one. This is precisely the outcome induced by the competitive equilibrium.

Next, we show that no individual $i$ has an incentive to deviate from the offer profile $w=\left(\left(p, q_{i}\right)\right)$. We consider deviations for buyers, since the proof for sellers is symmetric. We classify possible individual deviations for $i \in B$ from $w$ into three categories, and show that none of them is profitable.

(i) Consider $w_{i}^{\prime}=\left(p, q_{i}^{\prime}\right)$ such that $Q_{i} \ni q_{i}^{\prime} \neq q_{i}$. In any outcome with positive probability after that deviation, the utility for $i$ is $u_{i}(y,-p y)$ for some $y \in Q_{i}$. Since $q_{i} \in \arg \max _{q \in Q_{i}} u_{i}(q,-p q)$, we have that the expected utility after the deviation cannot be larger.

(ii) Consider $w_{i}^{\prime}=\left(p_{i}^{\prime}, q_{i}^{\prime}\right)$ such that $q_{i}^{\prime} \in Q_{i}$ and $p_{i}^{\prime}<p$. Since every seller $s \in S$ is asking $\widetilde{p}_{s}=p$, by proposition 1 we must have that in any outcome with positive probability after that deviation $y_{i}=0$. But then the expected utility after the deviation is 0 , and since $q_{i} \in \arg \max _{q \in Q_{i}} u_{i}(q,-p q)$, we have $u_{i}\left(q_{i},-p q_{i}\right) \geq$ $u_{i}(0,-p \times 0)=0$. 
(iii) Consider $w_{i}^{\prime}=\left(p_{i}^{\prime}, q_{i}^{\prime}\right)$ such that $q_{i}^{\prime} \in Q_{i}$ and $p_{i}^{\prime}>p$. Denote by $w^{\prime}$ the new offer profile. For any $y^{\prime} \in F\left(w^{\prime}\right)$, buyer $i$ gets a payoff of $u_{i}\left(y_{i}^{\prime},-p_{i}^{\prime} y_{i}^{\prime}\right)$. Since $p_{i}^{\prime}>p$ and $u_{i}(q,-p q)$ is decreasing in $p$,

$$
u_{i}\left(y_{i}^{\prime},-p_{i}^{\prime} y_{i}^{\prime}\right)<u_{i}\left(y_{i}^{\prime},-p y_{i}^{\prime}\right)
$$

Since $q_{i} \in \arg \max _{q \in Q_{i}} u_{i}(q,-p q)$,

$$
u_{i}\left(y_{i}^{\prime},-p y_{i}^{\prime}\right) \leq u_{i}\left(q_{i},-p q_{i}\right)
$$

Thus

$$
u_{i}\left(y_{i}^{\prime},-p_{i}^{\prime} y_{i}^{\prime}\right)<u_{i}\left(q_{i},-p q_{i}\right)
$$

for all $y^{\prime} \in F\left(w^{\prime}\right)$. Therefore

$$
E u_{i}\left(w^{\prime}\right)<E u_{i}(w)
$$

Since there are no profitable deviations, $w$ is a Nash equilibrium.

\section{Proof of Theorem 2}

The proof comes in several steps. First we show that in a Nash equilibrium with active trading, all active traders in the same side of the market offer the same price. Next, we show that active traders on both sides offer the same price. Finally, we show that if there are at least two active traders in each side of the market, every trader plays a best response to the price offered by active traders, so the allocation or allocations induced with positive probability by the Nash equilibrium are competitive allocations corresponding to that price. Note that the 'thick market' condition (at least two active traders in the Nash equilibrium) is invoked only in the last step.

Lemma 1. In each Nash equilibrium, all active sellers offer the same price, and all active buyers offer the same price.

Proof. We prove the result for the sellers since the proof for the buyers is analogous. Take any offer profile $w^{*}$ such that two active sellers offer different prices $\bar{p}$ and $\underline{p}$, with $\bar{p}>p$. We can claim that the seller, say trader $l$, who offers $\left(\underline{p}, \widetilde{q}_{l}\right)$ would be better off submitting $\left(p^{\prime}, \widetilde{q}_{l}\right)$ such that $\underline{p}<p^{\prime}<\bar{p}$.

To see this, from proposition 3 , since there is another active seller offering the price $\bar{p}$, seller $l$ sells $\left|\widetilde{q}_{l}\right|$ units when she offers $w_{l}^{*}=\left(p, \widetilde{q}_{l}\right)$. We can show that seller $l$ sells $\left|\widetilde{q}_{l}\right|$ units as well when she offers $w^{\prime}=\left(p^{\prime}, \widetilde{q}_{l}\right)$. Suppose there is $y^{\prime} \in F\left(w^{\prime}\right)$ such that $y_{l}^{\prime}>\widetilde{q}_{l}$. As in the last step of the proof of proposition 3 , for any $y \in F\left(w^{*}\right)$ we have

$$
\sum_{i \in B} y_{i}=-\sum_{i \in S} y_{i}>-\sum_{i \in S} y_{i}^{\prime}=\sum_{i \in B} y_{i}^{\prime} .
$$

Therefore there must be an active buyer at $w^{*}$, say $b$, such that $y_{b}^{\prime}<y_{b} \leq \widetilde{q}_{b}$. From proposition 4 , we have $\widetilde{p}_{b} \geq \bar{p}$. But, from proposition 2 , at profile $w^{\prime}$ we have $y_{l}^{\prime}>\widetilde{q}_{l}$ and $y_{b}^{\prime}<\widetilde{q}_{b}$ implying $\widetilde{p}_{b}<p^{\prime}<\bar{p}$, a contradiction. 
Thus, by offering $\left(p^{\prime}, \widetilde{q}_{l}\right)$, seller $l$ gets

$$
u_{l}\left(\widetilde{q}_{l},-p^{\prime} \widetilde{q}_{l}\right)=-p^{\prime} \widetilde{q}_{l}-\sum_{j=1}^{\left|\widetilde{q}_{l}\right|} r_{l j}>-\underline{p} \widetilde{q}_{l}-\sum_{j=1}^{\left|\widetilde{q}_{l}\right|} r_{l j}
$$

where the last term is the payoff seller $l$ gets by offering $\left(p, \widetilde{q}_{l}\right)$. Hence the seller gets better off by offering $\left(p^{\prime}, \widetilde{q}_{l}\right)$, so that $w^{*}$ cannot be a Nash equilibrium.

In lemma 2, we establish that in fact, in each Nash equilibrium, all active traders offer the same price. This implies that arbitrage profits are zero in every Nash equilibrium.

Lemma 2. In each Nash equilibrium, all active traders offer the same price.

Proof. Consider an offer profile $w^{*}$ such that there is trade and such that all active buyers offer the same price, say $p_{b}$, and all active sellers offer the same price, say $p_{s}$. From lemma 1, we know that only such profiles, or some profiles such that there is no trade, can be Nash equilibria. By proposition 4 , we have $p_{s} \leq p_{b}$. We will show that if $p_{s}<p_{b}$, at least one active trader has an incentive to deviate, so that $w^{*}$ cannot be a Nash equilibrium.

If $p_{s}<p_{b}$, following proposition 5 , we have that either $y_{i}=\widetilde{q}_{i}$ for all $y \in F\left(w^{*}\right)$ for all $i \in A S\left(w^{*}\right)$, or $y_{i}=\widetilde{q}_{i}$ for all $y \in F\left(w^{*}\right)$ for all $i \in A B\left(w^{*}\right)$. Suppose $y_{i}=\widetilde{q}_{i}$ for all $y \in F\left(w^{*}\right)$ for all $i \in A S\left(w^{*}\right)$ (the argument for the other case is analogous). Note that if there are inactive sellers in $w^{*}$, for any such seller $h$ we have $\widetilde{p}_{h}>p_{s}$ or $\widetilde{q}_{h}=0$. If $\tilde{p}_{h}<p_{s}$, then following proposition 3 we have $y_{h}=\widetilde{q}_{h}$ for all $y \in F\left(w^{*}\right)$, so the seller can be inactive only if $\widetilde{q}_{h}=0$. If $\widetilde{p}_{h}=p_{s}$, according to proposition 6 there must be some $y \in F\left(w^{*}\right)$ that $y_{h}<0$ unless $\widetilde{q}_{h}=0$. Denote by $p_{\neg s}$ the lowest price offered with a non-zero quantity by inactive sellers, if there is any, and note that in that case $p_{\neg s}>p_{s}$.

We claim that if $p_{s}<p_{b}$, an active seller, say $a$, would have an incentive to deviate from $w_{a}^{*}=\left(p_{s}, \widetilde{q_{a}}\right)$ to $w_{a}^{\prime}=\left(p^{\prime}, \widetilde{q_{a}}\right)$, where $p^{\prime} \in\left(p_{s}, \min \left\{p_{b}, p_{\neg s}\right\}\right)$ if there are non-zero quantity inactive sellers, and $p^{\prime} \in\left(p_{s}, p_{b}\right)$ otherwise.

To prove the claim, we argue first that for any $y^{\prime} \in F\left(w^{\prime}\right)$ we have $y_{a}^{\prime}=\widetilde{q}_{a}$. Suppose there is a $y^{\prime} \in F\left(w^{\prime}\right)$ such that $y_{a}^{\prime}>\widetilde{q}_{a}$. Then, from proposition 3, inactive sellers at $w^{*}$ remain so at $w^{\prime}$ since $p_{\neg s}>p^{\prime}$. Therefore $\sum_{i \in S} y_{i}^{\prime}>\sum_{i \in S} y_{i}$ for every $y \in F\left(w^{*}\right)$. Thus, for any $y \in F\left(w^{*}\right)$,

$$
\sum_{i \in B} y_{i}^{\prime}=-\sum_{i \in S} y_{i}^{\prime}<-\sum_{i \in S} y_{i}=\sum_{i \in B} y_{i}
$$

Therefore there must be an active buyer at $w^{*}$, say $h$, who offers $p_{b}$ and gets $y_{h}^{\prime}<y_{h} \leq$ $\widetilde{q}_{h}$. But, from proposition 2, at profile $w^{\prime}$ we have $y_{a}^{\prime}>\widetilde{q}_{a}$ and $y_{h}^{\prime}<\widetilde{q}_{h}$ implying $p_{b}<p^{\prime}$, a contradiction.

From the previous argument, by offering $w^{\prime}$ instead of $w^{*}$, seller $a$ is allocated $\widetilde{q}_{a}$, and gets a utility of

$$
u_{a}\left(\widetilde{q}_{a},-p^{\prime} \widetilde{q}_{a}\right)=-p^{\prime} \widetilde{q}_{a}-\sum_{j=1}^{\left|\widetilde{q}_{a}\right|} r_{a j}>-p_{s} \widetilde{q}_{a}-\sum_{j=1}^{\left|\widetilde{q}_{a}\right|} r_{a j}=u_{a}\left(\widetilde{q}_{a},-p_{s} \widetilde{q}_{a}\right) .
$$


Hence seller $a$ gets better off by offering $w^{\prime}$, so that $w^{*}$ cannot be a Nash equilibrium.

The next auxiliary result shows that traders must be indifferent between all positive probability outcomes induced by a Nash equilibrium.

Lemma 3. In each Nash equilibrium, every trader is indifferent between all outcomes that occur with positive probability.

Proof. Consider an offer profile $w^{*}$ such that all active traders, if there is any, offer the same price, say $p$. From lemma 2, we know that only such profiles can be Nash equilibria if trades happen with positive probability. Take trader $a$, a seller, for example. If seller $a$ is inactive, then her utility is 0 for any positive probability outcome. Suppose $a$ is active, and moreover there are $y, y^{\prime \prime} \in F\left(w^{*}\right)$ that $u_{a}\left(y_{a},-p y_{a}\right)>u_{i}\left(y_{a}^{\prime \prime},-p y_{a}^{\prime \prime}\right)$. We can show that in this case, $w$ cannot be a Nash equilibrium.

Since $F\left(w^{*}\right)$ is finite, there is some $y^{*} \in F\left(w^{*}\right)$ such that

$$
u_{a}\left(y_{a}^{*},-p y_{a}^{*}\right) \geq u_{a}\left(y_{a},-p y_{a}\right)
$$

for all $y \in F\left(w^{*}\right)$ and moreover

$$
u_{a}\left(y_{a}^{*},-p y_{a}^{*}\right)>u_{a}\left(y_{a}^{\prime \prime},-p y_{a}^{\prime \prime}\right)
$$

Since $y^{\prime \prime}$ has positive probability, $u_{a}\left(y_{a}^{*},-p y_{a}^{*}\right)>E u_{a}(w)$. By continuity, there is some $p^{\prime}<p$ such that

$$
u_{a}\left(y_{a}^{*},-p y_{a}^{*}\right)>u_{a}\left(y_{a}^{*},-p^{\prime} y_{a}^{*}\right)>E u_{a}(w) .
$$

We claim that if seller $a$ offers $w_{a}^{\prime}=\left(y_{a}^{*}, p^{\prime}\right)$, then $y_{a}^{\prime}=y_{a}^{*}$ for every $y^{\prime} \in F\left(w^{\prime}\right)$, so that the seller obtains $u_{a}\left(y_{a}^{*},-p^{\prime} y_{a}^{*}\right)$ which is a profitable deviation from $w^{*}$ by the inequality above. The claim implies that $w^{*}$ cannot be a Nash equilibrium. To verify the claim, suppose first that there is another seller $h$ that is active at $w^{\prime}$; since seller $h$ offers the price $p>p^{\prime}$, the claim follows from proposition 3. Suppose that no other seller is active at $w^{\prime}$, then if $y_{a}^{\prime}>y_{a}^{*}$ we get for any $y^{\prime} \in F\left(w^{\prime}\right)$,

$$
\sum_{i \in B} y_{i}^{\prime}=-\sum_{i \in S} y_{i}^{\prime}<-\sum_{i \in S} y_{i}^{*}=\sum_{i \in B} y_{i}^{*} .
$$

Then there must be some buyer, say $b$, such that $y_{b}^{\prime}<y_{b}^{*} \leq \widetilde{q}_{b}$. Since there is also a seller, seller $a$, such that $y_{a}^{\prime}>y_{a}^{*}$ and moreover this seller offers a price $p^{\prime}$ below the price offered by the buyer, we get a contradiction with proposition 2 .

From previous results, in any Nash equilibrium with active trade, all active traders offer the same price. In the next lemma we show that, in any Nash equilibrium with two or more traders per side, all traders get allocated quantities satisfying the utility maximization condition in the definition of competitive equilibrium.

Lemma 4. In every positive probability outcome of a Nash equilibrium with active trading, given the price offered by all active traders, all non-active traders are allocated utility-maximizing quantities. 
Proof. In the proof of this and the following lemmas, let $w^{*}$ be a Nash equilibrium with active trading, and (invoking lemma 2) let $p^{*}$ be the price offered by all active traders. We focus on sellers; the proof for the buyers is analogous.

As shown in the second paragraph of lemma 2, non-active sellers offer $\widetilde{p}_{i}>p^{*}$ or $\widetilde{q}_{i}=0$. Therefore, they get $y_{i}=0$ for all $y \in F\left(w^{*}\right)$, and thus obtain $E u_{i}\left(w^{*}\right)=0$. We claim that for inactive sellers, $y_{i}=0$ is utility-maximizing given price $p^{*}$. Equivalently, we claim that $r_{i 1} \geq p^{*}$.

To see this, suppose trader $i$ is an inactive seller and $r_{i 1}<p^{*}$. Consider a deviation for $i$ to $w_{i}^{\prime}=\left(p^{*},-1\right)$. By proposition 6 , if seller $i$ is inactive under the offer profile $w^{\prime}$, so is every seller in $A S\left(w^{*}\right)$ under the offer profile $w^{\prime}$, and by proposition 3 so is every seller. But this would violate proposition 2 , since there are trades in each side of the market active under $w^{*}$ and thus offering $p^{*}$ should induce positive probability to trade. Hence, there exists $y^{\prime} \in F\left(w^{\prime}\right)$ such that $y_{i}^{\prime}=-1$. Since $u_{i}\left(y_{i}^{\prime},-p^{*} y_{i}^{\prime}\right)=p^{*}-r_{i 1}>0$, by deviating to offer $\left(p^{*},-1\right)$, agent $i$ would have $E u_{i}\left(w^{\prime}\right)>0$, so that $w^{*}$ would not be a Nash equilibrium.

Lemma 5. In every positive probability outcome of a Nash equilibrium with active trading, given the price offered by all active traders, all active traders are allocated quantities that are either utility-maximizing or involve less in absolute value than the utility-maximizing trade.

Proof. For a given active seller, say $s$, let $\underline{\delta}_{s}$ and $\bar{\delta}_{s}$ be the minimal and the maximal element, respectively, of the set

$$
\arg \max _{q_{s} \in Q_{s}} u_{s}\left(q_{s},-p^{*} q_{s}\right)
$$

so that $-k \leq \underline{\delta}_{s} \leq \bar{\delta}_{s} \leq 0$. From the utility maximization problem, it follows that every $x \in Q_{s}$ such that $\underline{\delta}_{s} \leq x \leq \bar{\delta}_{s}$ is also a utility maximizer.

We claim that for every $y \in F\left(w^{*}\right)$ we have $y_{s} \geq \underline{\delta}_{s}$ so that either the seller is allocated an optimal trade or a smaller (in absolute value) than optimal trade. For suppose there is $y \in F\left(w^{*}\right)$ such that $y_{s}<\underline{\delta}_{s}$ so that $u_{s}\left(y_{s},-p^{*} y\right)<u_{s}\left(\underline{\delta}_{s},-p^{*} \underline{\delta}_{s}\right)$. If $\underline{\delta}_{s}=0$ or $p^{*}=0$, it follows that $u_{s}\left(y_{s},-p^{*} y\right)<0$, and by lemma $3, E u_{s}\left(w^{*}\right)<0$. But then trader $s$ can deviate to $\left(p^{*}, 0\right)$ and guarantee an expected utility of zero, so that $w^{*}$ cannot be a Nash equilibrium. Suppose instead that $\underline{\delta}_{s}<0$ and $p^{*}>0$. By continuity, there is some $p^{\prime}<p^{*}$ such that

$$
u_{s}\left(y_{s},-p^{*} y\right)<u_{s}\left(\underline{\delta}_{s},-p^{\prime} \underline{\delta}_{s}\right)<u_{s}\left(\underline{\delta}_{s},-p^{*} \underline{\delta}_{s}\right) .
$$

Now consider a deviation by $s$ to $w_{s}^{\prime}=\left(p^{\prime}, \underline{\delta}_{s}\right)$. We show that such deviation guarantees $y_{s}^{\prime}=\underline{\delta}_{s}$ for all $y^{\prime} \in F\left(w^{\prime}\right)$, so that by Lemma 3,E$u_{s}\left(w^{\prime}\right)=u_{s}\left(\underline{\delta}_{s},-p^{\prime} \underline{\delta}_{s}\right)>E u_{s}\left(w^{*}\right)$. To see this, suppose there is some $y^{\prime} \in F\left(w^{\prime}\right)$ such that $y_{s}^{\prime}>\underline{\delta}_{s}$. Since $p^{\prime}<p^{*}$, and all other sellers offer a price equal or larger than $p^{*}$ or a quantity equal to zero, it follows from proposition 3 that for all other $i \in S$ we have $y_{i}^{\prime}=0$. Therefore

$$
\sum_{i \in B} y_{i}=-\sum_{i \in S} y_{i} \geq-y_{s}>-\underline{\delta}_{s}=-\sum_{i \in S} y_{i}^{\prime}=\sum_{i \in B} y_{i}^{\prime} .
$$


But then there must be a buyer, say $a$, such that $y_{a}^{\prime}<y_{a} \leq \widetilde{q}_{a}$ offering price $p^{*}>p^{\prime}$, contradicting proposition 2 .

Lemma 6. In every positive probability outcome of a Nash equilibrium with active trading, given the price offered by all active traders, if there are two or more active traders on the same side of the market, then all traders on this side of the market are allocated utility-maximizing quantities.

Proof. We claim that if there are at least two active sellers, then every $y \in F\left(w^{*}\right)$ satisfies $\underline{\delta}_{s} \leq y_{s} \leq \bar{\delta}_{s}$ and is therefore a utility maximizer.

In lemma 5 we have shown in every positive probability allocation $y$, active sellers are allocated quantities that are either utility-maximizing given the price or involve less trade $\left(\underline{\delta}_{s} \leq y_{s} \leq 0\right)$ so we need only focus on active sellers.

Now suppose there are two active sellers, say $s$ and $h$. If $y_{s}<\underline{\delta}_{s}$ for any $y \in F\left(w^{*}\right)$, we have that $w^{*}$ cannot be a Nash equilibrium by the previous step. If $\underline{\delta}_{s} \leq y_{s} \leq \bar{\delta}_{s}$, the claim follows from lemma 3 . In the last part of this proof, we show that if there is a $y \in F\left(w^{*}\right)$ such that $y_{s}>\bar{\delta}_{s}, w^{*}$ cannot be a Nash equilibrium.

Since $\left|y_{s}\right|<\left|\bar{\delta}_{s}\right|$, from the utility maximization problem we must have $r_{\left|y_{s}\right|+1}<p^{*}$. Hence $u_{s}\left(y_{s}-1,-p^{*}\left(y_{s}-1\right)\right)-u_{s}\left(y_{s},-p^{*} y_{s}\right)=p^{*}-r_{\left|y_{s}\right|+1}>0$. By continuity, there is some $p^{\prime}<p^{*}$ such that

$$
\left.u_{s}\left(y_{s},-p^{*} y\right)<u_{s}\left(y_{s}-1,-p^{\prime}\left(y_{s}-1\right)\right)<u_{s}\left(y_{s}-1,-p^{*}\left(y_{s}-1\right)\right)\right) .
$$

Also, for any $y, y^{\prime \prime} \in F\left(w^{*}\right)$, we have $y_{s}=y_{s}^{\prime \prime}$. Suppose there exists $y, y^{\prime \prime} \in F\left(w^{*}\right)$ such that $y_{s}<y_{s}^{\prime \prime}$, then

$$
u_{s}\left(y_{s}^{\prime \prime},-p^{*} y_{s}^{\prime \prime}\right)-u_{s}\left(y_{s},-p^{*} y_{s}\right)=-p^{*}\left(y_{s}^{\prime \prime}-y_{s}\right)+\sum_{j=\left|y_{s}^{\prime \prime}\right|+1}^{\left|y_{s}\right|} r_{s j}<0
$$

contradicting lemma 3.

Now consider a deviation by $s$ to $w_{s}^{\prime}=\left(p^{\prime}, y_{s}-1\right)$. We show that such deviation guarantees $y_{s}^{\prime}=y_{s}-1$ for all $y^{\prime} \in F\left(w^{\prime}\right)$, so that by Lemma $3, E u_{s}\left(w^{\prime}\right)=u_{s}\left(y_{s}-\right.$ $\left.1,-p^{\prime}\left(y_{s}-1\right)\right)>E u_{s}\left(w^{*}\right)$. To see this, suppose there is some $y^{\prime} \in F\left(w^{\prime}\right)$ such that $y_{s}^{\prime}>y_{s}-1$. Since $p^{\prime}<p^{*}$, and all other sellers offer a price equal or larger than $p^{*}$ or a quantity equal to zero, it follows from proposition 3 that for all other $i \in S$ we have $y_{i}^{\prime}=0$. Therefore, take any $y^{\prime \prime} \in F\left(w^{*}\right)$ such that $y_{h}^{\prime \prime}<0$,

$$
\sum_{i \in B} y_{i}^{\prime \prime}=-\sum_{i \in S} y_{i}^{\prime \prime} \geq-y_{s}-y_{h}^{\prime \prime} \geq-y_{s}+1>-y_{s}^{\prime}=-\sum_{i \in S} y_{i}^{\prime}=\sum_{i \in B} y_{i}^{\prime}
$$

But then there must be a buyer, say $a$, such that $y_{a}^{\prime}<y_{a}^{\prime \prime} \leq \widetilde{q}_{a}$ offering price $p^{*}>p^{\prime}$, contradicting proposition 2 .

Since the market clearing condition in the equilibrium definition is satisfied by any allocation induced by any offer profile, theorem 2 follows from lemma 6 . 


\section{Proof of Theorem 3}

First we prove the condition in the statement of the theorem is sufficient. Suppose $w^{*}$ is a Nash equilibrium with active trading, and suppose there are at least two intramarginal sellers and at least two weakly intramarginal buyers. (The other case is analogous.) From lemma 1 and lemma 2, all active traders offer the same price, say $p^{*}$. Denote $\underline{\delta}_{i}$ and $\bar{\delta}_{i}$ the minimal and maximal element, respectively, of the set

$$
\arg \max _{q_{i} \in Q_{i}} u_{i}\left(q_{i},-p^{*} q_{i}\right) .
$$

From lemma 5, for any $y \in F\left(w^{*}\right)$, we have $\underline{\delta}_{i} \leq y_{i} \leq 0$ for every active seller $i$, and $0 \leq y_{i} \leq \bar{\delta}_{i}$ for every active buyer $i$, and moreover from lemma 4 , non-active traders acquire utility-maximizing quantities given $p^{*}$. That is, no one trades in excess of their utility-maximizing quantity.

Consider first the case $p^{*}>v_{s}$. We claim that every intramarginal seller must be active. For suppose an intramarginal seller $i$ is not active; then the seller is making a payoff equal to zero in every allocation $y \in F\left(w^{*}\right)$. But by deviating unilaterally to $w_{i}^{\prime}(p, 1)$ for any $v_{s}<p<p^{*}$, the seller can guarantee herself a positive payoff $u_{i}(-1, p)=-r_{i 1}+p>-v_{s}+p^{*}>0$ in every allocation with positive probability given the new offer profile. Hence, two or more sellers are active in $w^{*}$. If two or more buyers are active in $w^{*}$, then applying theorem $2, p^{*}$ is a competitive price and all the outcomes from the Nash equilibrium are competitive.

If only one buyer is active in $w^{*}$, say buyer $a$, we must have that at least one weakly intramarginal buyer, say buyer $c$, who is not active in $w^{*}$. Since $c$ is not active in $w^{*}$, we must have $p^{*} \geq r_{c 1}$; otherwise $c$ has a profitable deviation. Therefore $p^{*} \geq r_{c 1} \geq p$. If $p^{*}>\bar{p}$, then for every $y \in F\left(w^{*}\right)$,

$$
\sum_{i \in B} y_{i} \leq \sum_{i \in B} \overline{\boldsymbol{\delta}}_{i}<-\sum_{i \in S} \underline{\boldsymbol{\delta}}_{i} \leq-\sum_{i \in S} y_{i}
$$

violating the allocation rule of the clearing house. The first and the last inequality comes from lemma 6 which implies that for all the active sellers $y_{i} \in\left[\underline{\delta}_{i}, \bar{\delta}_{i}\right]$ since there are at least two of them, and from lemma 5 which implies that for any active buyer $y_{i} \leq \bar{\delta}_{i}$. The strict inequality in the middle is a result of the price being higher than any competitive price. Hence $p \leq p^{*} \leq \bar{p}$ so that $p^{*}$ is a competitive price.

Now suppose that there is an allocation $y \in F\left(w^{*}\right)$ such that $y_{a}<\underline{\delta}_{a}$. Since $p^{*}$ is competitive, in any competitive equilibrium allocation $\left(q_{i}\right)$, we have $-\sum_{i \in S} q_{i} \geq \underline{\delta}_{a}$. Thus in every competitive equilibrium at price $p^{*}$, there exists at least one seller $s$ that has $q_{s}<y_{s}$. Since $y_{s}, q_{s} \in\left[\underline{\boldsymbol{\delta}}_{s}, \overline{\boldsymbol{\delta}}_{s}\right]$, we have $r_{s,\left|q_{s}\right|}=p^{*}$. Hence for any competitive equilibrium at $p^{*}$, there is at least a traded unit with reservation value $p^{*}$ for a seller. By definition of $v_{s}$ this implies $p^{*} \leq v_{s}$, a contradiction to the assumption. Therefore for the only active buyer $a, y_{a} \in\left[\underline{\delta}_{a}, \bar{\delta}_{a}\right]$ for every $y \in F\left(w^{*}\right)$. Hence, all traders obtain utility-maximizing quantities given $p^{*}$, and every outcome $y \in F\left(w^{*}\right)$ is competitive.

Consider the remaining case $p^{*} \leq v_{s}$. Since $p^{*}<r_{1 i}$ for every weakly intramarginal buyer, it follows that there are at least two active buyers in Nash equilibrium and moreover every buyer chooses utility-maximizing quantities given $p^{*}$. As in the previous proof, if there are two or more active sellers, then, from theorem 2, all outcomes in 
$F\left(w^{*}\right)$ are competitive. Similarly, if there is a unique active seller $a$ and $y_{a} \in\left[\underline{\boldsymbol{\delta}}_{a}, \overline{\boldsymbol{\delta}}_{a}\right]$ for every $y \in F\left(w^{*}\right)$, then all traders obtain utility-maximizing quantities given $p^{*}$, and every outcome $y \in F\left(w^{*}\right)$ is competitive. The remaining case is that there is a unique active seller $a$ and $\bar{\delta}_{a}<y_{a}<0$, so that

$$
\sum_{i \in B} y_{i}=-y_{s}<-\bar{\delta}_{s} .
$$

Suppose $p^{*}=v_{s}=\underline{p}$. Since $p^{*}$ is a competitive price, in every competitive equilibrium allocation $\left(q_{i}\right)$, we have $\sum_{i \in B} q_{i} \geq-\bar{\delta}_{s}$; i.e. aggregate demand should be able to meet an individual seller's supply. Thus in every competitive equilibrium at $p^{*}$, there exists at least one buyer $b$ that has $q_{b}>y_{b}$. Since $y_{b}, q_{b} \in\left[\underline{\delta}_{b}, \bar{\delta}_{b}\right]$, we have $r_{b, q_{b}}=p^{*}$. Hence in every competitive equilibrium at $p^{*}$, there is at least one traded unit with reservation value $p^{*}$ for a buyer. By definition of $v_{b}$, this implies $p^{*} \geq v_{b}$. Using $v_{b}>v_{s}$ we get a contradiction to the assumption $p^{*}=v_{s}$.

Finally, suppose $p^{*}=v_{s}<\underline{p}$ or $p^{*}<v_{s}$. In either case, $p^{*}<\underline{p}$, and

$$
-\sum_{i \in S} y_{i} \leq-\sum_{i \in S} \bar{\delta}_{i}<\sum_{i \in B} \underline{\delta}_{i} \leq \sum_{i \in B} y_{i}
$$

violating the allocation rule of the clearing house. The first and the last inequality comes from lemma 5 which implies that for any active seller $y_{i} \geq \underline{\delta}_{i}$ and from lemma 6 which implies that for all the active buyers $y_{i} \in\left[\underline{\delta}_{i}, \bar{\delta}_{i}\right]$ since there are at least two of them. The strict inequality in the middle is a result of the price being lower than any competitive price.

This finishes the proof of sufficiency. We now prove that the condition is necessary. Since at least two units are traded in every competitive equilibrium, there is at least one intramarginal trader on each side of the market. Possible violations of the condition in the theorem are

(a) There are two or more intramarginal traders on one side of the market, and only one weakly intramarginal trader on the other side;

(b) There are two or more weakly intramarginal traders on one side of the market, among whom only one is intramarginal, and only one weakly intramarginal trader on the other side;

(c) There is only one weakly intramarginal trader on each side of the market.

We provide a counterexample for each of those scenarios, illustrating that there are outcomes of Nash equilibria with trade that are not competitive.

(a) Consider the economy $S=\{1,2\}, B=\{3,4\}, k=2$, and $r_{11}=r_{21}=2, r_{12}=r_{22}=$ $4, r_{31}=r_{32}=3, r_{41}=r_{42}=1$. The competitive price range is [2,3], and in every competitive equilibrium there are two units traded. The marginal values are $v_{s}=2$, $v_{b}=3$. Seller 1 , seller 2 and buyer 3 are intramarginal traders, while buyer 4 is not weakly intramarginal. The offer profile $w=((2,-1),(2,0),(2,1),(1,0))$ is a Nash equilibrium, and it induces with probability one the allocation $(-1,0,1,0)$, which is not competitive. 
(b) Consider the economy $S=\{1,2\}, B=\{3,4\}, k=2$, and $r_{11}=r_{12}=2, r_{21}=$ $r_{22}=3, r_{31}=r_{32}=4, r_{41}=r_{42}=1$. The competitive price range is [2,3], and in every competitive equilibrium there are two units traded. The marginal values are $v_{s}=2, v_{b}=4$. Seller 1 and buyer 3 are intramarginal traders, seller 2 is weakly intramarginal, and buyer 4 is not weakly intramarginal. The offer profile $w=$ $((2,-1),(2,0),(2,1),(1,0))$ is a Nash equilibrium and it induces with probability one the allocation $(-1,0,1,0)$, which is not competitive.

(c) Consider the economy $S=\{1,2\}, B=\{3,4\}, k=2$, and $r_{11}=r_{12}=2, r_{21}=r_{22}=$ $4, r_{31}=r_{32}=3, r_{41}=r_{42}=1$. The competitive price range is [2,3], and in every competitive equilibrium there are two units traded. The marginal values are $v_{s}=2$, $v_{b}=3$. Seller 1 and buyer 3 are intramarginal traders, and neither seller 2 nor buyer 4 are weakly intramarginal. The offer profile $w=((2,-1),(2,0),(2,1),(1,0))$ is a Nash equilibrium, and it induces with probability one the allocation $(-1,0,1,0)$, which is not competitive. 


\section{Appendix B. Instructions and Quizes}

\section{B.1.1 Instructions for $\mathrm{CH}$ treatments Instructions}

Welcome to today's experiment! You have earned $\$ 5$ for showing up on time. The following instructions will explain how you can make decisions and earn more money, so please read them carefully. During the experiment, please keep your cell phone turned off, and refrain from talking to other participants. If at some point you have a question, please raise your hand, and we will address it with you privately.

In the experiment, you will be grouped anonymously with three other participants, whose identities will not be revealed. Two of the participants in your group will be buyers, and the other two will be sellers. Your group and your role will remain the same throughout the experiment. Your role will be revealed to you at the beginning of the experiment.

There will be 20 formal rounds. In each round, each of the two buyers has the opportunity to buy up to 2 units of the good from the two sellers in the same group, and each of the two sellers has the opportunity to sell up to 2 units of the good to the two buyers in the same group.

Obtaining each unit of the good generates a value for the buyer, and selling each unit of the good incurs a cost to the seller. The values to a buyer and the costs to a seller may vary by unit. Values may vary between buyers and costs may vary between sellers.

Your own values (if you are a buyer) or costs (if you are a seller) will be revealed to you at the beginning of the experiment. Your values/costs remain constant throughout the experiment. The values/costs of other participants will NOT be revealed to you.

\section{Payoffs}

The values and costs are in US Dollars. A buyer's payoff in one round equals the value she obtains from the unit(s) she buys minus the total price she pays for her purchase. A seller's payoff in one round equals the revenue she gets from the sale minus the cost incurred for the unit(s) she sells.

Buyer's payoff $=$ value obtained from purchase - payment for purchase

Seller's payoff $=$ revenue from sale - cost incurred for sale

For example, suppose Buyer A generates a value of $\$ 4$ from buying the first unit, and $\$ 3$ from buying the second. If Buyer A obtains 2 units at the unit price of $\$ 2$, then

$$
\text { Buyer A's payoff }=\underbrace{(\$ 4+\$ 3)}_{\text {Values }}-\underbrace{(\$ 2+\$ 2)}_{\text {Payment }}=\$ 3
$$

Suppose Seller A sells 1 unit at the price of $\$ 5.6$, and her cost is $\$ 1$ for selling the first unit and $\$ 3$ for selling the second. Then

$$
\text { Seller A’s payoff }=\underbrace{\$ 5.6}_{\text {Revenue }}-\underbrace{\$ 1}_{\text {Cost }(\mathrm{s})}=\$ 4.6
$$


Since Seller A does not sell the second unit, only the cost of the first unit incurs.

If a participant does not trade in a round, her payoff from that round is $\$ 0$.

The payoffs from different rounds do not accrue. At the end of the experiment, one of the 20 formal rounds will be randomly chosen. Your total earnings in this experiment will be your payoff from the chosen round, plus the $\$ 5$ show-up bonus.

\section{How to trade}

Each group trades in its own market. In each round, the market opens for 2 minutes, during which each participant can submit an offer. In a buying offer, a buyer submits a unit price, together with how many units ( 1 or 2 ) she would like to buy for that price. In a selling offer, a seller submits a unit price, and how many units ( 1 or 2 ) she would like to sell for that price. The offer you submit will NOT be shown to any other participant.

Please note that you can submit only ONE offer in each round, and you cannot revise your offer once you submit it.

After two minutes, or once every participant has submitted a unit price and quantity, transactions will be determined under the rules below, as demonstrated in the following example.

\section{Example}

Suppose the submitted offers are as follows.

Buyer A: buying offer for 1 unit, at the unit price of $\$ 3$

Buyer B: buying offer for 2 units, at the unit price of $\$ 1$

Seller A: selling offer for 1 unit, at the unit price of $\$ 4$

Seller B: selling offer for 1 unit, at the unit price of $\$ 2$.

Please note that this example is only for demonstration of the procedure, the submitted offers will NOT be shown to any participant in the experiment.

- Sort Orders Firstly, buying offers and selling offers will be sorted separately. If an offer contains two units (eg. Buyer B's offer), it will be split into TWO IDENTICAL offers, each containing one unit. Buying offers for each unit will be queued in descending order, and selling offers for each unit will be queued in ascending order, as the following table shows.

\begin{tabular}{c|c}
\hline Buying offers for one unit (high to low) & Selling offers for one unit (low to high) \\
\hline$\$ 3$ (from Buyer A) & $\$ 2$ (from Seller B) \\
$\$ 1$ (from Buyer B) & $\$ 4$ (from Seller A) \\
$\$ 1$ (from Buyer B) & \\
\hline
\end{tabular}

In case of tied buying offers or tied selling offers, the order of them will be randomly determined.

- Trade Units After the orders are sorted, each buying offer and selling offer at the same position in the queues will be compared. As long as the buying price is no lower than the selling price, the corresponding buyer and seller make a trade.

The first buying offer in the queue ( $\$ 3$ from Buyer $A$ ) and the first selling offer ( $\$ 2$ from Seller B) make a trade since $3>2$. The second buying offer and selling 
offer cannot trade since the buying price ( $\$ 1$ from Buyer B) is lower than the selling price ( $\$ 4$ from Seller $\mathrm{A}$ ). The third buying offer cannot be fulfilled since there is not a selling offer corresponding to it. By this procedure, the buying offer with higher price is more likely to be fulfilled, and so is the selling offer with lower price.

- Prices When a trade happens, the buyer will pay the price she offered and get one unit of the good, and the seller will receive the price she asked for and sell one unit of the good. In this example, one unit of the good is traded. Buyer A pays $\$ 3$ for the unit she bought, as she offered to. Seller B gets $\$ 2$ for the unit she sells, as she asked for.

In each round, a participant who does not submit any offer will not make any trade. To prevent losing money, a buyer/seller cannot submit an offer that could cause a loss for her.

\section{Summary of Each Round}

The market for each group opens at the beginning of each round. After each participant in your group submits an offer or when the market closes, you will be informed of how many units you trade, and your payoff in the current round. Also, the price(s) for each traded unit in your market will be revealed anonymously to all participants in your group. You will NOT be informed of the buying/selling offers that do not result in trade.

This is the end of the instructions. We now proceed to a quiz to ensure everyone understands the instructions. The experiment will begin after everyone gives a correct answer to each question. Before the formal rounds begin, there will be a practice round, which does not count towards payment.

Again, if you have any question at any point of the experiment, please raise your hand and an experimenter will assist you.

\section{B.1.2 Quiz for CH treatments}

\section{Quiz}

1. True or False. Circle your answers.

Your role (buyer or seller) will remain the same in all of the rounds.

Your group does not change throughout the experiment.

In each round, you can revise your offer after you submit it.

Your costs or values will not change between rounds.

Your offer in each round will not be shown to other participants.

2. Suppose the offers submitted are as follows.

Buyer A: buying offer for 2 units, at the unit price of $\$ 3$

Buyer B: buying offer for 1 unit, at the unit price of $\$ 5$ 
Seller A: selling offer for 2 units, at the unit price of $\$ 1$

Seller B: selling offer for 1 unit, at the unit price of $\$ 2$.

(a) Use the procedure demonstrated in the instructions, fill out the buying and selling offers in the table.

\begin{tabular}{c|c}
\hline Buying offers for one unit (high to low) & Selling offers for one unit (low to high) \\
\hline$\$ \quad \begin{array}{c}\text { (from Buyer B) } \\
\text { (from Buyer }\end{array}$ & $\begin{array}{l}\$ 1 \text { (from Seller A) } \\
\$ 1 \text { (from Seller A) }\end{array}$ \\
\hline$\$ 3$ (from Buyer A) & $\$ \quad$ (from Seller \\
\hline
\end{tabular}

(b) How many units does Buyer A buy? unit(s)

(c) How much does Buyer A pay for the unit(s) she buys in total ? \$

(d) Suppose the first unit Buyer A obtains will generate a value of $\$ 5$ to her, and the second unit she obtains will generate $\$ 4$. What is Buyer A's payoff here?

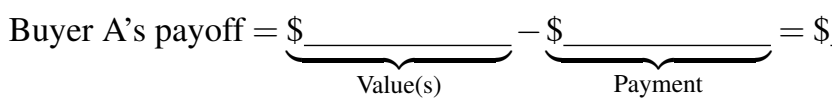

(e) Suppose the first unit Seller B sells will cost her $\$ 0.5$, and the second unit she sells will cost \$2.5. What is Seller B's payoff here?

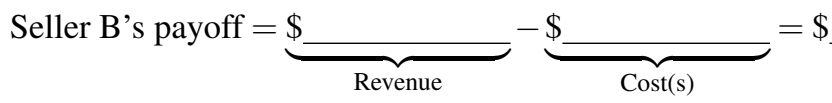

\section{B.2.1 Instructions for DA treatments Instructions}

Welcome to today's experiment! You have earned \$5 for showing up on time. The following instructions will explain how you can make decisions and earn more money, so please read them carefully. During the experiment, please keep your cell phone turned off, and refrain from talking to other participants. If at some point you have a question, please raise your hand, and we will address it with you privately.

In the experiment, you will be grouped anonymously with three other participants, whose identities will not be revealed. Two of the participants in your group will be buyers, and the other two will be sellers. Your group and your role will remain the same throughout the experiment. Your role will be revealed to you at the beginning of the experiment.

There will be 20 formal rounds. In each round, each of the two buyers has the opportunity to buy up to 2 units of the good from the two sellers in the same group, and each of the two sellers has the opportunity to sell up to 2 units of the good to the two buyers in the same group. 
Obtaining each unit of the good generates a value for the buyer, and selling each unit of the good incurs a cost to the seller. The values to a buyer and the costs to a seller may vary by unit. Values may vary between buyers and costs may vary between sellers.

Your own values (if you are a buyer) or costs (if you are a seller) will be revealed to you at the beginning of the experiment. Your values/costs remain constant throughout the experiment. The values/costs of other participants will NOT be revealed to you.

\section{Payoffs}

The values and costs are in US Dollars. A buyer's payoff in one round equals the value she obtains from the unit(s) she buys minus the total price she pays for her purchase. A seller's payoff in one round equals the revenue she gets from the sale minus the cost incurred for the unit(s) she sells.

Buyer's payoff $=$ value obtained from purchase - payment for purchase

Seller's payoff $=$ revenue from sale - cost incurred for sale

For example, suppose Buyer A generates a value of $\$ 4$ from buying the first unit, and $\$ 3$ from buying the second. If Buyer A obtains the first unit at the price of $\$ 2$ and the second unit at the price of $\$ 1$, then

$$
\text { Buyer A's payoff }=\underbrace{(\$ 4+\$ 3)}_{\text {Values }}-\underbrace{(\$ 2+\$ 1)}_{\text {Payment }}=\$ 4
$$

Suppose Seller A sells 1 unit at the price of \$5.6, and her cost is \$1 for selling the first unit and $\$ 3$ for selling the second. Then

$$
\text { Seller A's payoff }=\underbrace{\$ 5.6}_{\text {Revenue }}-\underbrace{\$ 1}_{\text {Cost(s) }}=\$ 4.6
$$

Since Seller A does not sell the second unit, only the cost of the first unit incurs.

If a participant does not trade in a round, her payoff from that round is $\$ 0$.

The payoffs from different rounds do not accrue. At the end of the experiment, one of the 20 formal rounds will be randomly chosen. Your total earnings in this experiment will be your payoff from the chosen round, plus the $\$ 5$ show-up bonus.

\section{How to trade}

Each group trades in its own market. In each round, the market opens for a maximum of two minutes, during which each participant can submit offers. In a buying offer, a buyer submits a price she is willing to buy a unit at. In a selling offer, a seller submits a price she is willing to sell a unit at. For each participant, only after her first unit is traded can she trade her second unit.

The timer on the screen counts down the time remaining for the current round. The timer starts from two minutes at the beginning of each round, then jumps to 20 seconds once a participant attempts to submit an offer, and restarts from 20 seconds every time a participant attempts to submit an offer. The round finishes if two minutes elapse, or if no new attempt occurs within 20 seconds of the last attempt, whichever occurs first.

The attached pages are screen shots of the interface for a seller and a buyer in the same market. Screen shot 1 is for the seller. Screen shot 2 is for the buyer. 
From left to right in the upper part of the interface are the Submit Your Offer section, where you can enter the price for each of your offers; the section for general information, where you can see the number of rounds, your role, time remaining in the current round, and your real-time payoff in the current round; Your Values/Costs section, where you can see the values or costs for your units and whether they are traded or not.

On the lower part of the interface, from left to right are the Selling Offers section, which lists the selling offers from low to high; the Buying Offers section, which lists the buying offers from high to low; the Transactions section, which displays all transactions in your market in the current round. Your own offers and transactions will be highlighted on the lists.

\section{- How to Sell}

\section{- Offer to Sell}

You can offer to sell one unit by submitting a price in the Submit Your Offer section. When you make an offer, the price has to be lower than the lowest selling offer at the time, which is the top one on the Selling Offers list. If you make a new offer, it will replace your previous offer.

As shown in the screen shots, the lowest selling offer is $\$ 3$, so if any of the sellers wants to make a new offer, she has to offer a price lower than $\$ 3$.

To prevent losing money, you cannot submit an offer that could cause a loss for you.

\section{- Accept A Buying Offer}

You can sell one unit by submitting a price equal to the highest buying offer, which is the top one on the Buying Offers list. By doing so, you sell the unit to the buyer and incur the cost, the buyer pays you the price you submitted. (If you submit a price lower than the highest buying offer, you sell the unit at the price you submit.) In the example from the screen shots, the highest buying offer is $\$ 2$, if a seller submits an offer of $\$ 2$, she sells the unit to the buyer, and the buyer pays her $\$ 2$.

\section{- Transactions}

There are two ways you sell one unit. Your selling offer is accepted by a buyer, or you accept a buying offer. When you sell one unit, your offer for that unit will be removed from the list, the transaction will be recorded, and your payoff will be updated. Then you may offer to sell your second unit or accept another buying offer on the list. The rules are the same as for the first unit.

\section{- How to Buy}

\section{- Offer to Buy}

You can offer to buy one unit by submitting a price in the Submit Your Offer section. When you make an offer, the price has to be higher than the highest buying offer at the time, which is the top one on the Buying Offers list. If you make a new offer, it will replace your previous offer. 
As shown in the screen shots, the highest buying offer is $\$ 2$, so if any of the buyers wants to make a new offer, she has to offer a price higher than $\$ 2$.

To prevent losing money, you cannot submit an offer that could cause a loss for you.

\section{- Accept A Selling Offer}

You can buy one unit by submitting a price equal to the lowest selling offer, which is the top one on the Selling Offers list. By doing so, you buy the unit from the seller and obtain the value, and pay the seller the price you submitted. (If you submit a price higher than the lowest selling offer, you buy the unit at the price you submit.) In the example from the screen shots, the lowest selling offer is $\$ 3$, if a buyer submits an offer of $\$ 3$, she buys the unit from the seller, and pays the seller $\$ 3$.

\section{- Transactions}

There are two ways you buy one unit. Your buying offer is accepted by a seller, or you accept a selling offer. When you buy one unit, your offer for that unit will be removed from the list, the transaction will be recorded, and your payoff will be updated. Then you may offer to buy your second unit or accept another selling offer on the list. The rules are the same as for the first unit.

\section{Summary of Each Round}

The market for each group opens at the beginning of each round. A seller can make selling offers, or accept buying offers, by submitting prices on the interface. A buyer can make buying offers, or accept selling offers, by submitting prices on the interface. When an offer is accepted, a transaction happens. Offers, transactions and your payoff in the current round will be displayed on your screen.

This is the end of the instructions. We now proceed to a quiz to ensure everyone understands the instructions. The experiment will begin after everyone gives a correct answer to each question. Before the formal rounds begin, there will be one practice round, which does not count towards payment.

Again, if you have any question at any point of the experiment, please raise your hand and an experimenter will assist you. 


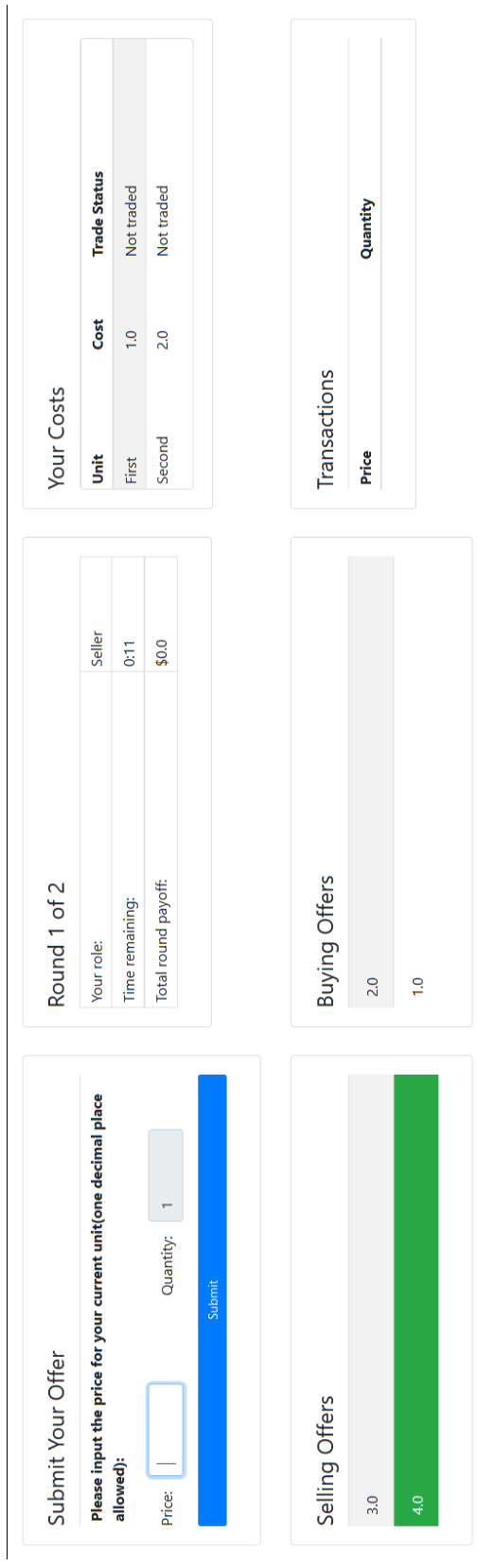

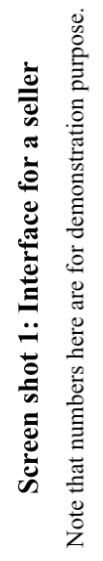




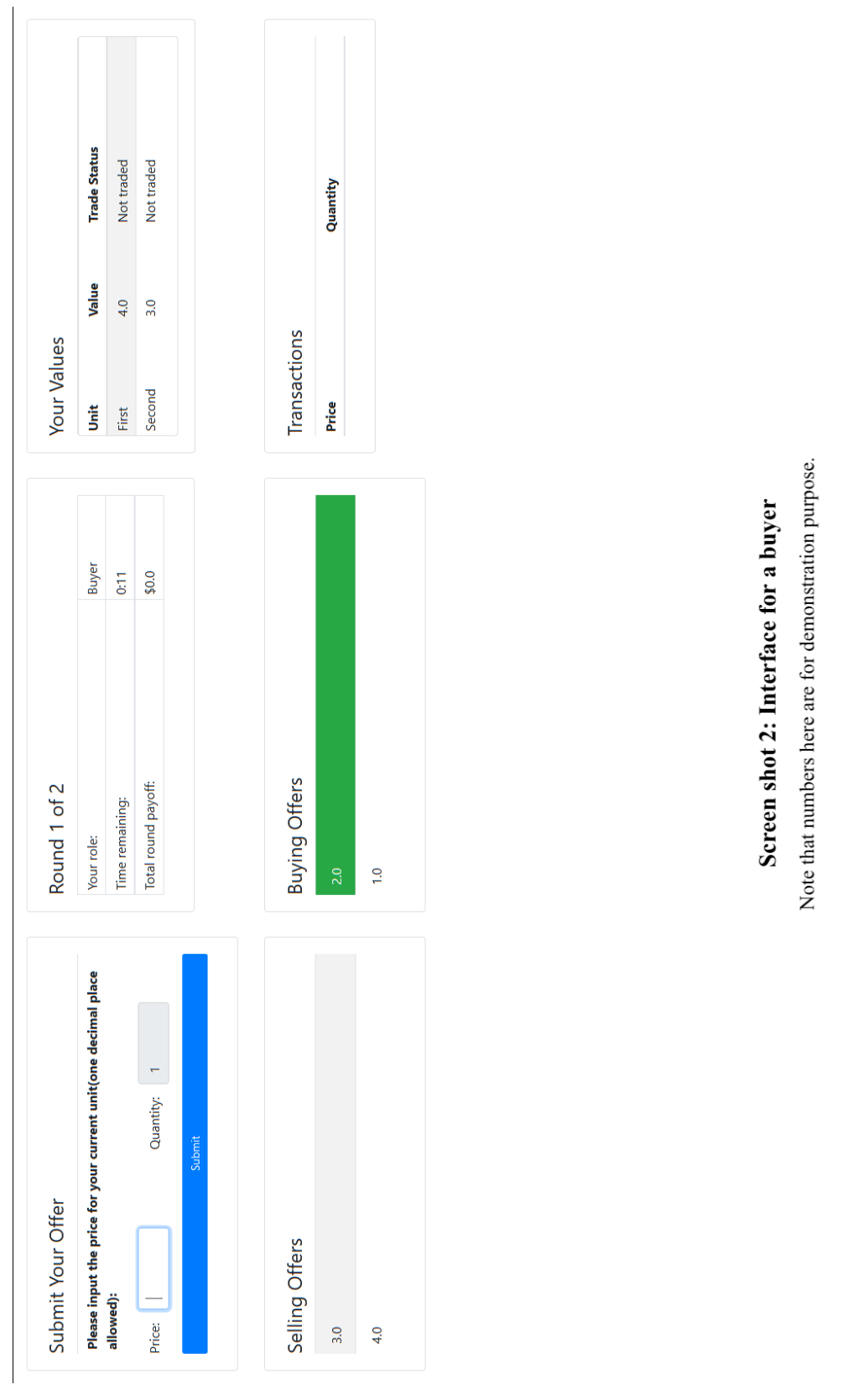




\section{B.2.2 Quiz for DA treatments}

\section{Quiz}

1. True or False. Circle your answers.

$\begin{array}{llll}\text { Your role (buyer or seller) will remain the same in all of the rounds. } & \text { T } & F\end{array}$

$\begin{array}{lll}\text { Your group does not change throughout the experiment. } & T & F\end{array}$

$\begin{array}{lll}\text { Your costs or values will not change between rounds. } & T & F\end{array}$

$\begin{array}{llll}\text { You can submit offers for both of your units at the same time. } & \text { T } & \text { F }\end{array}$

2. Suppose you are a buyer, and the lists of offers are as follows. Your offer is highlighted.

\begin{tabular}{|c|c|}
\hline Selling Offers & Buying Offers \\
\cline { 2 - 2 }$\$ 4$ & $\$ 3$ \\
$\$ 5$ & $\$ 1$ \\
\hline
\end{tabular}

(a) Which of the following prices can you submit as a new offer? Circle your answer.
A. 2
B. 0.5
C. 3.7
D. 1.5

(b) Which of the following prices can you submit to accept the selling offer of $\$ 4$ ? Circle you answer.
A. 4
B. 2.5
C. 1.2
D. 3

(c) If you accept the lowest selling offer on the list, and your values for the first and second unit are $\$ 7$ and $\$ 6$ respectively, what is your payoff?

$$
\text { Your payoff }=\underbrace{\$ \_}_{\text {Value }(\mathrm{s})}-\underbrace{\$}_{\text {Payment }}=\$
$$

3. Suppose you are a seller, and the lists of offers are as follows. Your offer is highlighted.

\begin{tabular}{|c|c|}
\hline Selling Offers & Buying Offers \\
\hline$\$ 4$ & $\$ 3$ \\
$\$ 5$ & $\$ 1$ \\
\hline
\end{tabular}

(a) Which of the following prices can you submit as a new offer? Circle your answer.
A. 6
B. 2.1
C. 4
D. 5

(b) Which of the following prices can you submit to accept the buying offer of $\$ 3$ ? Circle you answer.
A. 3.5
B. 4.1
C. 5
D. 3

(c) Suppose the first and second unit you sell will cost $\$ 0.1$ and $\$ 0.4$ respectively, and you accept both buying offers on the list. What is your payoff?

$$
\text { Your payoff }=\underbrace{\$ \_}_{\text {Revenue }}-\underbrace{\$}_{\text {Cost }(\mathrm{s})}=\$
$$




\section{Appendix C. Additional Tables and Graphs}

\begin{tabular}{|c|c|c|c|c|}
\hline & $(1)$ & $(2)$ & $(3)$ & $(4)$ \\
\hline & CH Competitive & CH Monopoly & DA Competitive & DA Monopoly \\
\hline \multirow[t]{2}{*}{$\alpha_{1}$} & $14.50^{* * *}$ & $8.772^{* * *}$ & $16.31^{* * *}$ & 6.972 \\
\hline & $(1.586)$ & $(2.022)$ & $(0.770)$ & $(3.853)$ \\
\hline \multirow[t]{2}{*}{$\alpha_{2}$} & $9.312^{* * *}$ & $12.29^{* * *}$ & 3.233 & $20.67^{* * *}$ \\
\hline & $(1.369)$ & $(1.692)$ & $(2.577)$ & $(3.197)$ \\
\hline \multirow[t]{2}{*}{$\alpha_{3}$} & $11.15^{* * *}$ & $10.31^{* * *}$ & $8.215^{* * *}$ & $15.97^{* * *}$ \\
\hline & $(1.382)$ & $(0.858)$ & $(0.835)$ & $(1.060)$ \\
\hline \multirow[t]{2}{*}{$\alpha_{4}$} & $5.353^{* *}$ & $24.17^{* * *}$ & $8.009^{* *}$ & 9.949 \\
\hline & $(1.953)$ & $(4.723)$ & $(2.480)$ & $(8.398)$ \\
\hline \multirow[t]{2}{*}{$\alpha_{5}$} & $14.73^{* * *}$ & $6.849^{* * *}$ & $14.93^{* * *}$ & $19.63^{* * *}$ \\
\hline & $(1.260)$ & $(1.341)$ & $(1.034)$ & $(3.957)$ \\
\hline \multirow[t]{2}{*}{$\alpha_{6}$} & $8.747^{* * *}$ & $14.85^{* * *}$ & $18.74^{* * *}$ & $13.00^{* * *}$ \\
\hline & $(1.931)$ & $(1.231)$ & $(1.337)$ & $(2.271)$ \\
\hline \multirow[t]{2}{*}{$\alpha_{7}$} & 5.745 & $21.48^{* * *}$ & $8.513^{* *}$ & $35.36^{* * *}$ \\
\hline & $(3.765)$ & $(2.548)$ & $(2.612)$ & $(5.466)$ \\
\hline \multirow[t]{2}{*}{$\alpha_{8}$} & 5.853 & $9.953^{* * *}$ & 4.514 & $6.294^{*}$ \\
\hline & $(3.216)$ & $(0.737)$ & $(2.781)$ & $(2.768)$ \\
\hline \multirow[t]{2}{*}{$\alpha_{9}$} & $9.997^{* * *}$ & $17.21^{* * *}$ & $18.11^{* * *}$ & $18.15^{* * *}$ \\
\hline & $(1.455)$ & $(1.690)$ & $(1.550)$ & $(3.558)$ \\
\hline \multirow[t]{2}{*}{$\alpha_{10}$} & $11.21^{* * *}$ & $16.01^{* * *}$ & $17.76^{* * *}$ & 2.920 \\
\hline & $(1.836)$ & $(0.0988)$ & $(1.271)$ & $(3.150)$ \\
\hline \multirow[t]{2}{*}{$\alpha_{11}$} & $13.60^{* * *}$ & $16.94^{* * *}$ & $16.47^{* * *}$ & $18.20^{* * *}$ \\
\hline & $(1.425)$ & $(0.591)$ & $(1.209)$ & $(1.511)$ \\
\hline \multirow{2}{*}{$\alpha_{12}$} & $10.52^{* * *}$ & $9.367^{* * *}$ & $17.05^{* * *}$ & $21.73^{* * *}$ \\
\hline & $(2.572)$ & $(1.597)$ & $(1.092)$ & $(2.055)$ \\
\hline \multirow[t]{2}{*}{$\alpha_{13}$} & $8.582^{* * *}$ & -1.491 & $18.59^{* * *}$ & -0.645 \\
\hline & $(1.849)$ & (3.979) & $(1.398)$ & $(6.926)$ \\
\hline \multirow[t]{2}{*}{$\alpha_{14}$} & $13.62^{* * *}$ & 7.344 & $10.47^{*}$ & \\
\hline & $(1.733)$ & $(4.756)$ & $(4.248)$ & \\
\hline \multirow[t]{2}{*}{$\alpha_{15}$} & $9.627^{* * *}$ & $15.02^{* * *}$ & & \\
\hline & $(0.886)$ & $(3.018)$ & & \\
\hline \multirow[t]{2}{*}{$\alpha_{16}$} & $9.522^{* * *}$ & $9.851^{* * *}$ & & \\
\hline & $(1.135)$ & $(2.662)$ & & \\
\hline \multirow[t]{2}{*}{$\alpha_{17}$} & $8.857^{* * *}$ & & & \\
\hline & $(1.978)$ & & & \\
\hline \multirow[t]{2}{*}{$\beta$} & $16.12^{* * *}$ & $16.02^{* * *}$ & $16.98^{* * *}$ & $19.20^{* * *}$ \\
\hline & $(0.228)$ & $(0.0611)$ & $(0.171)$ & $(0.353)$ \\
\hline Obs. & 283 & 259 & 272 & 231 \\
\hline
\end{tabular}

Notes: Standard errors in parentheses. $* * *, * *, *$ for significance levels of $0.1 \%, 1 \%$ and $5 \%$ respectively. Market specified AR(1) was used.

Table 7: Regressions for the price trend by treatment 


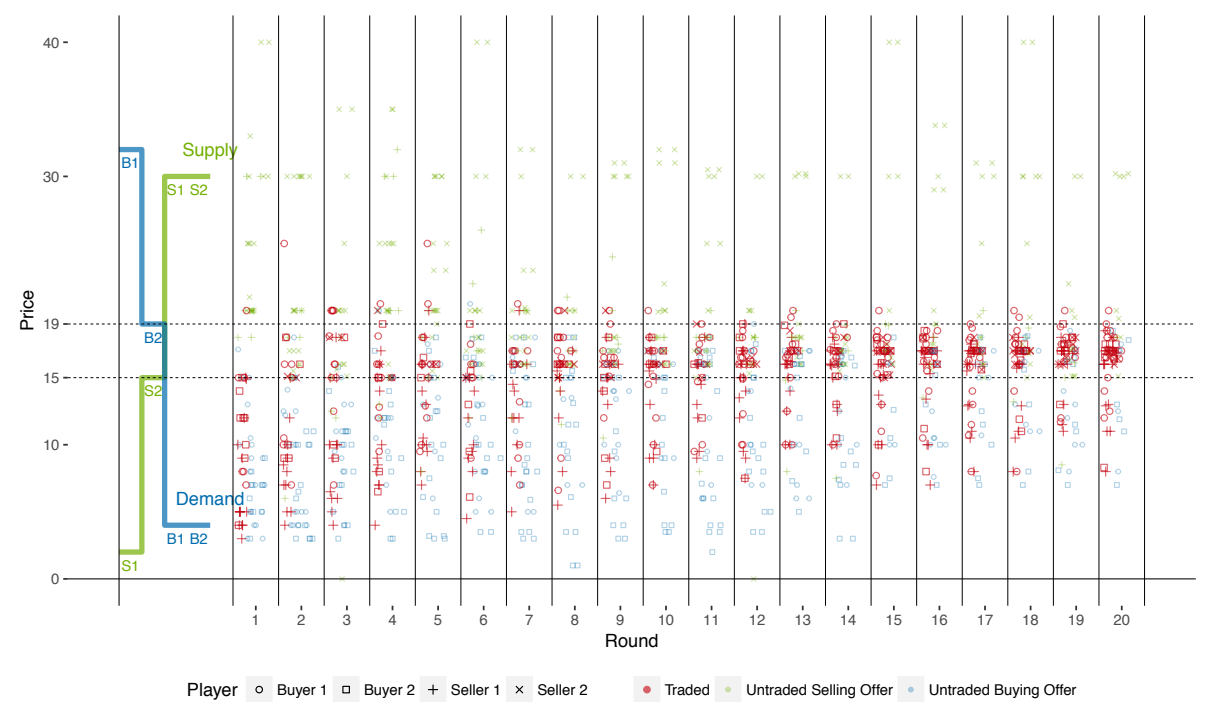

Figure 10: Offers under $\$ 45$ and prices in $\mathrm{CH}$ Competitive treatment

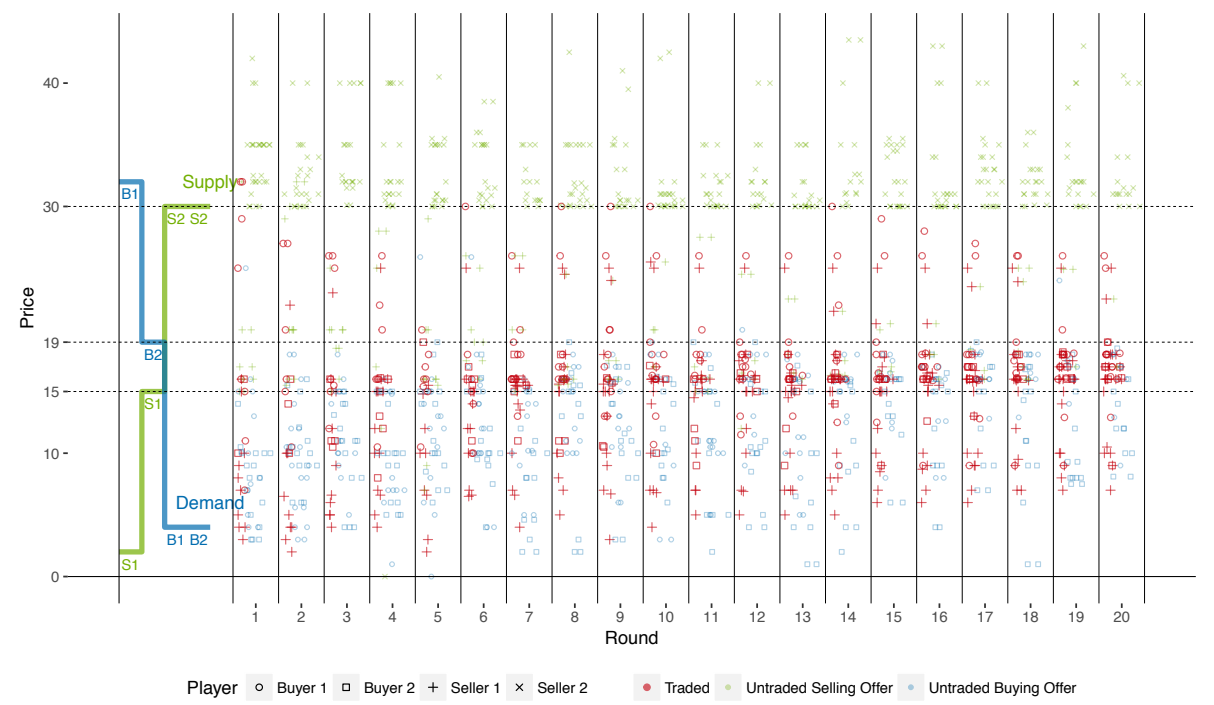

Figure 11: Offers under $\$ 45$ and prices in $\mathrm{CH}$ Monopoly treatment 


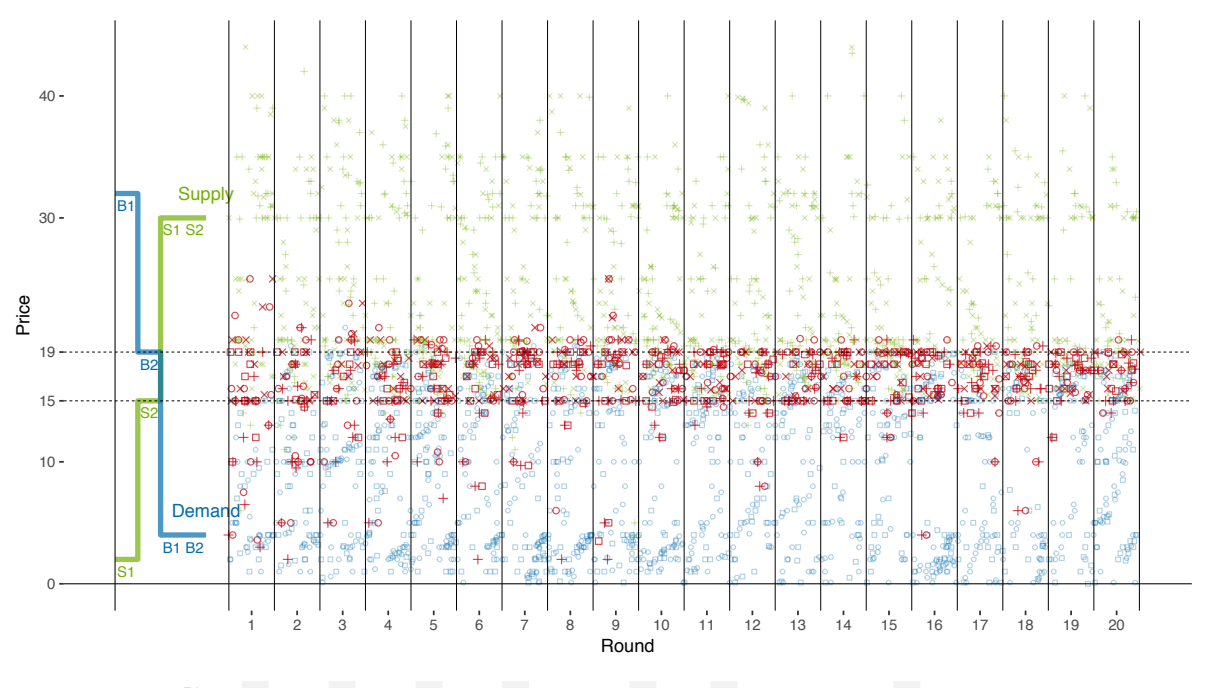

Figure 12: Offers under $\$ 45$ and prices in DA Competitive treatment

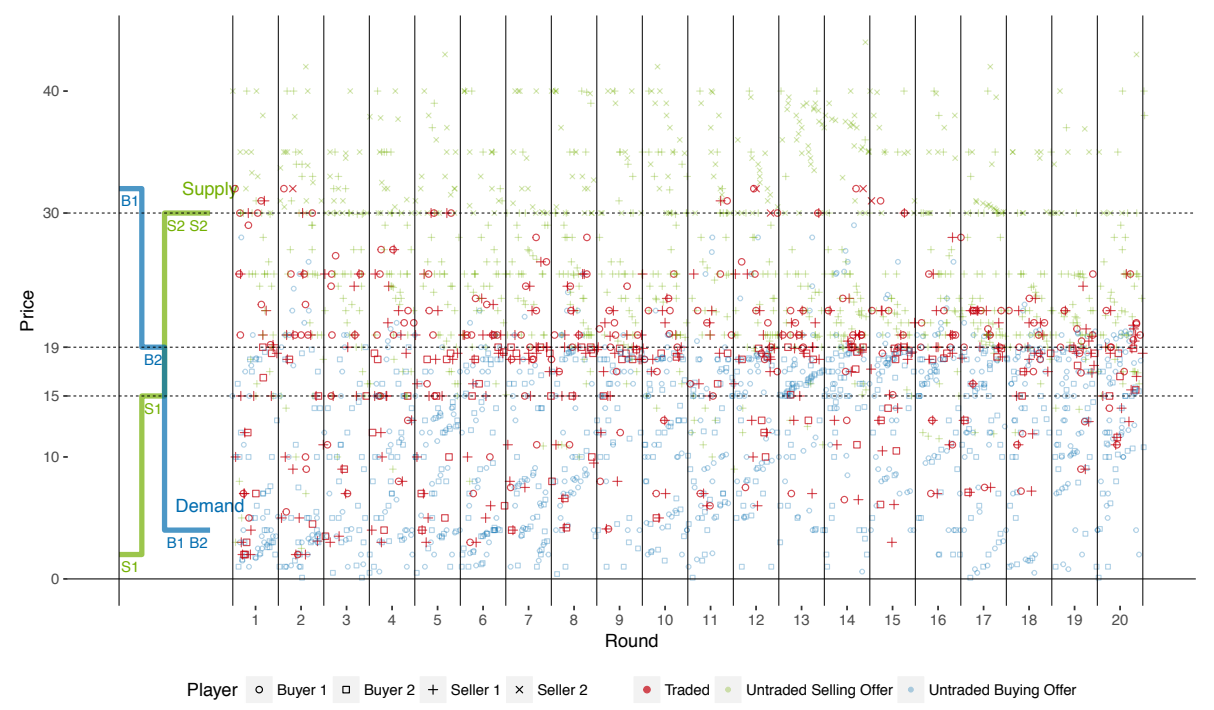

Figure 13: Offers under $\$ 45$ and prices in DA Monopoly treatment 


\section{References}

Baumol, W., J. C. Panzar, and R. D. Willig (1982). Contestable Markets and the Theory of Industry Structure. San Diego: Harcourt Brace Jovanovich.

Benassy, J.-P. (1986). On competitive market mechanisms. Econometrica 54(1), 95108.

Bertrand, J. L. F. (1883). Théorie des Richesses: revue de Théories mathématiques de la richesse sociale par Léon Walras et Recherches sur les principes mathématiques de la théorie des richesses par Augustin Cournot. Journal des Savants, 499-508.

Cason, T. N. and D. Friedman (1996). Price formation in double auction markets. Journal of Economic Dynamics and Control 20(8), 1307-1337.

Cason, T. N. and T. Sharma (2001). Durable goods, Coasian dynamics, and uncertainty: Theory and experiments. Journal of Political Economy 109(6), 1311-1354.

Chen, D. L., M. Schonger, and C. Wickens (2016). oTree-An open-source platform for laboratory, online, and field experiments. Journal of Behavioral and Experimental Finance 9, 88-97.

Coase, R. H. (1972). Durability and monopoly. Journal of Law and Economics 15(1), 143-149.

Cournot, A.-A. (1838). Recherches sur les principes mathématiques de la théorie des richesses. Paris: chez L. Hachette.

Davis, D. D. and C. A. Holt (1994). Market power and mergers in laboratory markets with posted prices. Rand Journal of Economics, 467-487.

Dubey, P. (1982). Price-quantity strategic market games. Econometrica 50(1), 111126.

Dubey, P. and M. Shubik (1980). A strategic market game with price and quantity strategies. Journal of Economics 40(1), 25-34.

Friedman, D. and J. Ostroy (1995). Competitivity in auction markets: An experimental and theoretical investigation. Economic Journal 105(428), 22-53.

Hayek, F. A. (1945). The use of knowledge in society. American Economic Review 35(4), 519-530.

Holt, C. A. (1995). Industrial organization: A survey of laboratory research. In J. H. Kagel and A. E. Roth (Eds.), The Handbook of Experimental Economics, pp. 349444. Princeton, NJ: Princeton University Press.

Kachelmeier, S. J. and M. Shehata (1992). Culture and competition: A laboratory market comparison between China and the West. Journal of Economic Behavior \& Organization 19(2), 145-168. 
Kimbrough, E. O. and A. Smyth (2018). Testing the boundaries of the double auction: The effects of complete information and market power. Journal of Economic Behavior \& Organization 150, 372-396.

Laughlin, G., A. Aguirre, and J. Grundfest (2014). Information transmission between financial markets in Chicago and New York. Financial Review 49(2), 283-312.

Noussair, C. N., C. R. Plott, and R. G. Riezman (1995). An experimental investigation of the patterns of international trade. American Economic Review 85(3), 462-491.

Plott, C., N. Roy, and B. Tong (2013). Marshall and Walras, disequilibrium trades and the dynamics of equilibration in the continuous double auction market. Journal of Economic Behavior \& Organization 94, 190-205.

Porter, R. (1991). A review essay on Handbook of Industrial Organization. Journal of Economic Literature 29(2), 553-72.

Selten, R. (1991). Properties of a measure of predictive success. Mathematical Social Sciences 21(2), 153-167.

Simon, L. K. (1984). Bertrand, the Cournot paradigm and the theory of perfect competition. Review of Economic Studies 51(2), 209-230.

Smith, V. L. (1980). Relevance of laboratory experiments to testing resource allocation theory. In J. Kmenta and J. B. Ramsey (Eds.), Evaluation of Econometric Models, pp. 345-377. New York: Academic Press.

Smith, V. L. (1981). An empirical study of decentralized institutions of monopoly restraint. In G. Horwich and J. Quirk (Eds.), Essays in Contemporary Fields of Economics in Honor of Emanuel T. Weiler (1914-1979), pp. 83-106. West Lafayette: Purdue University Press.

Smith, V. L. (1982). Markets as economizers of information: experimental examination of the "Hayek hypothesis". Economic Inquiry 20(2), 165-179.

Smith, V. L. and A. W. Williams (1990). The boundaries of competitive price theory: Convergence, expectations, and transaction costs. In L. Green and J. H. Kagel (Eds.), Advances in Behavioral Economics, Volume 2, Chapter 2, pp. 31-53. New York: Ablex Publishing.

Smith, V. L., A. W. Williams, W. K. Bratton, and M. G. Vannoni (1982). Competitive market institutions: Double auctions vs. sealed bid-offer auctions. American Economic Review 72(1), 58-77. 